Portland State University

PDXScholar

\title{
Die Idee der neuen Welt in Fritz von Unruhs Trilogie Ein Geschlecht
}

Paul Otto Soumokil

Portland State University

Follow this and additional works at: https://pdxscholar.library.pdx.edu/open_access_etds

Part of the German Literature Commons Let us know how access to this document benefits you.

\section{Recommended Citation}

Soumokil, Paul Otto, "Die Idee der neuen Welt in Fritz von Unruhs Trilogie Ein Geschlecht" (1970). Dissertations and Theses. Paper 916.

https://doi.org/10.15760/etd.916

This Thesis is brought to you for free and open access. It has been accepted for inclusion in Dissertations and Theses by an authorized administrator of PDXScholar. Please contact us if we can make this document more accessible: pdxscholar@pdx.edu. 
AN ADSTRACT OF THE THESIS OT Paul Otto Soumokil for the Master of Arts in German presented April 20, 1970.

Title: Die Idee der neuen Welt in Fritz von Unruhs Trilogie Ein Creschlecht.

APPROVED BY MEMBERS OF THE THESIS COMMITTEE:

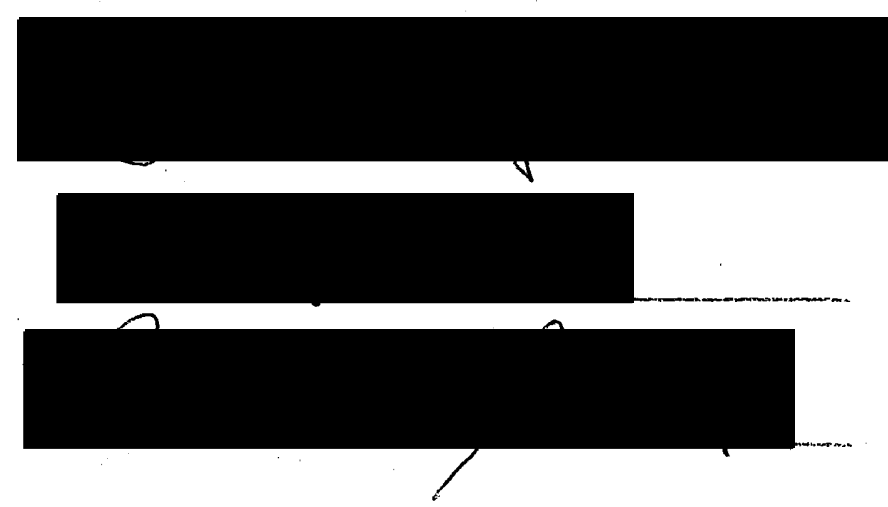

Fritz: von Unruh, who lives at Oranienhof in Diez an der Lahn, was born iri 1885 . He wrote the first two parts of his trilogy Ein Gescblecht during the literary movement in Germany which is known as "Expressionismus". The yet unpublished third part was not finished until 1958. It was in this trilogy that he developed his ideas of a new wordd.

The uheaval and destruction of World War I shattered the complacency of life and traditions which had so long been ingrained in Europe. This tramatic experience resulted in a new examination of life, its meaning and sense. The stark reality in which Germany found herself after the war and the contradictory abundance of material, 
intellectual and spiritual striving in social and economic worlds appeared as a prelude for a new order in the woxld Gestalt. It was during this time that Unruh began work on his trilogy which was to incorporate his idea of a new world.

Two facts are especially important in the development of his ideas. First, he himself was of noble birth. The traditions of unquestionable service and loyalty to church and state were a part of him. The sense of duty which was deeply ingraired in him experienced, however, a fundamental change. This change became the nucleus for his trilogy. Secondly, his experiences as an officer in World War I served as an impetus in the development of his WeItanschaung.

His newly found idea of a new world may be seen as an evolving process which first finds expression in his war poem Vor der Entscheidung and is brought to realization in the trilogy. The central theme of this thesis is an interpretation of these works which will show the development of his ideas. They lead us from rebellion to chaos and to a new cosmos. 
DIE IDEE DER NEUEN WELT IN FRITZ VON UNRUHS

TRILOGIE EIN GESCHLECHT

by

PAUL, OTTO SOUMOKII

A thesis submitted in partial fulfillment of the requirements for the degree of

\author{
MASTER OF ARTS \\ in \\ GERMAN
}

\author{
Portland State University \\ 1970
}


TO THE OFEICE OF GRADUATE STUDIES:

The members of the Committee approved the thesis of Paul Otto Soumokil presented Apri1 20, 1970.

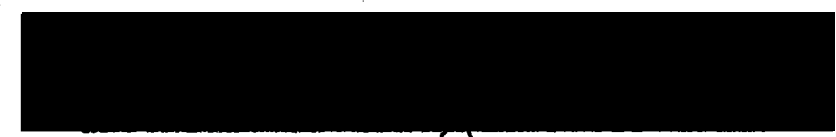

Franz Langhammer, Chairman

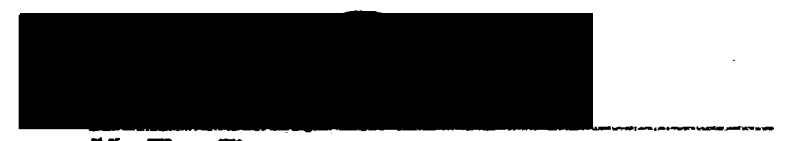

H.F. Peters

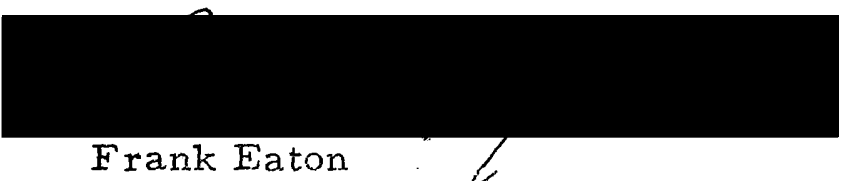

Frank Eaton

APPROVED:

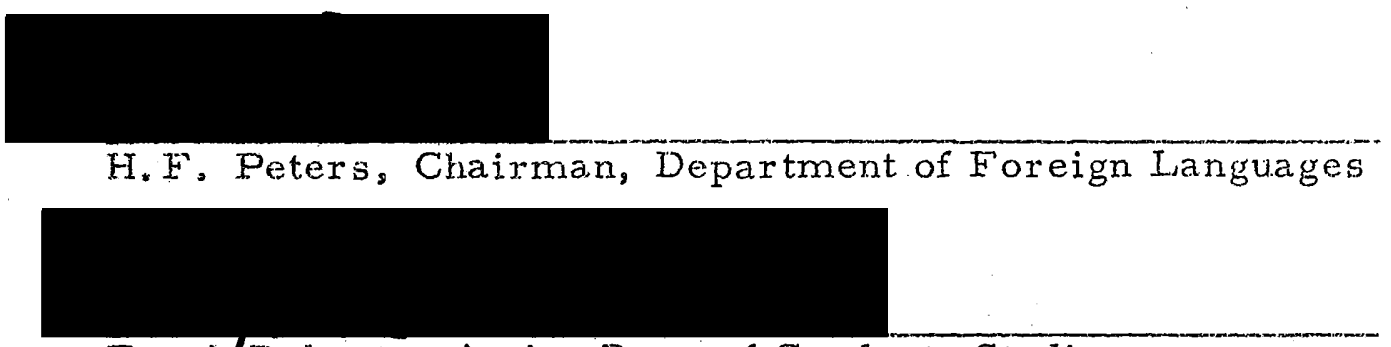

Frank Roberts, Acting. Dean of Graduate Studies

May 1, 1970 


\section{INHALT}

KAPITEI,

SEITE

I EINLEITUNG .......................

II DER JUNGE DJCH'TER UND DIE WELT . . . . . . . 6

A Als Kadett

1 Die Welt der: Realität

2 Die Welt der Ideale

B Als Offizier

1. Der Bruch mit der Pflicht

2 Die innere Wandlung

III DER RUF ZUM UMSTURZ IN DEM KRIEGSGEDICHT

"VOR DER ENTSCHEIDUNG" .............

A Die veraltete Pflicht

B Die Formulierung der neuen Pflicht

IV VOM CHAOS ZU EINEM NEUEN KOSMOS IN DER TRILOGIE

A Das Chaos in "Ein Geschlecht" ............

1. Die Mutter als die Welt

2. Der âlteste Sohn und die Tochter als die Vernichter der Weit

3 Die Mutter als die Gebärerin der neuen Welt

B Die Ordnung in "Platz".............. 40

1. Dietrich als die Kraft der neuen Welt

2 Irene als Untexstutzer dieser Kraft

3 Dietrich und Irene als Trager der neuen Weit.

C Der neue Kosmos in "Dietrich" ...........

1 Die Gestaltung der neuen Welt durch Friede

2 Die Gestaltung der neuen Welt durch Liebe 
KAPITEI,

SEITE

$\mathrm{V}$ DIE IDEE DER NEUEN WELT ............ 74

BIBLIOGRAPHIE $\ldots \ldots \ldots \ldots \ldots \ldots \ldots \ldots \ldots \ldots \ldots \ldots \ldots$ 


\section{KAPITEL I}

\section{EINLEITUNG}

Der erste Weltkrieg bedeutete für Europa, besonders für Deutschland, eine Erschüterung. Anscheinend erfreuten sich die Massen ihrer Ruhe wieder, aber die Erschütterung wirkte unablässig weiter und "us serte sich in einer Unzahl geistiger und ungeistiger Unternehmungen dex Zeit. Über dem Chaos der widerstrebenden Kräfte lag ein Gefth? eines neuen Werdens. Die Weit der deutschen Gegenwart, die gegensätzliche F'ulle der materiellen, intellektuellen und geistigen Bestrebungen in Wirtschaft, Wissenschaft und Politik erschienen als der Auftakt einer neuen Ordnung in der Welt. Es war in dieser Zeit, in der dis Wissenden im deutschen Volke den Menschen den Weg zu einer besseren Zukunft zeigen wollten.

Einer dieser Wissenden ist der Dichter Fritz von Unruh. In ihm, wie nur in wenigen, die sich an den Problemen der Zeit poetisch versuchten, kann man die Eigenschaften finden, die einen Dichter zum Sprecher, ja zum Lehrer und Propheten seiner Epoche machen. Er besass die grosse Kraft, zu erfiblen, woran die Menschen leiden. Er. ahnte, wie die Menschen in falsche Überlieferungen und veraltete Gedankengänge verotrickt waren und run ihren Schicksalsweg bis zur Ver-.. 
nichtung gehen müssen, wenn nicht Selbstbesinnung und Nächstenliebe Raum gewinnen. Und er hatte die Kraft, dem. Gefühl Ausdruck zu geben. Zwei Tatsachen treten fur seine Bewertung besonders hervor: Er ist der Sprössling eines Uradelsgeschlechtes und er war Offizier im ersten Weltkrieg. Fast alle Unruhs standen im Dienst des Staates. Ihr Motto war: "Ich dien !" In diesem Verhältnis setzte sich von Vater zu Sohn das Gesetz der Pflicht fort. Es ist diese Pflicht, von der sich Unruh später abkehrte. Er kehrte sich aber nicht bloss von ihr ab, er verwandelte sie und wie dieser Pflichtbegriff sich verwandelt und ver tieft ist exgreifend und ist der Kern von dem jede Betrachtung seines Schaffens ihren Ausgang nirnmt. 1

Die Tatsache, dass er Kriegsoffizier war, ist wichtig, da während des Krieges die Idee der neuen Welt in ihm entsprang. Während andere Dichter seiner Zeit über den Sieg schrieben, schrieb er "über die moralische Verwüstung, die der Krieg verursachte. Schon früh aber bemerkt der Dichter, dass die Welt nicht durch Gewalt, sondern durch Selbstbesinnung und Brüdexlichkeit neu gestaltet werden kann. Imrner gebieterischer wird deshalb im Schaffen Unruhs das Thema "Liebe", immex dringlicher das Problem "Mann und Weib". Um es so zu lósen, damit nach dem Massenmord des Krieges eine Wiedergeburt des Men-, schen möglich werden kann, muss der Einzelne mit sich selbst ins

1 Robert Meister, "Fritz von Unruh", Germanische Studien, 39. Heft (Berlin, 1925), S. 7 und 13. 
Reine kommen, und muss das Verhältnis von Mensch zu Mensch neu begründet werden. 1

Es ist diese Idee der Menschheit, die den Dichter zur hohen Reife brachte -- und es ist nicht so, als ob er sich den Geist der Humanität aus Zweckgründen gewählt hatte. Ihm stand keineWahl frei. Sein Menschentum schuf ihn zum Dichter. Und weil dieses Menschentum das Dichterische bestimmte, konnte es im Verlauf eines langen dichtexischen Lebens auch keinen Wechsel der Positionen geben. Mit Recht entsprechen ihm hier Goethe's Verse aus dem Divan:

Dein Lied ist drehend wie das Sternengew"llbe, Anfang und Ende immerfort dasselbe. Und was die Mitte bringt ist offenbar Das, was zu Ende bleibt und anfangs war ! 2

Von Überallher aus seinem Werk blickt uns sein Menschenbegriff an. Dieser Begriff steht hinter seinem Namen als eine exemplarische Lebensleistung. Er ist auch das Ergebnis eines ebenso exemplarischen Chaxakters und einer Willenskraft, die auf eine Umgestaltung der: Lebenswirklichkeit, die wiederum die neue Welt bewirken soll, gerichtet ist.

Der Dichter wählte den expressionistischen Stil. Er versuchte die

1 Friedrich Rasche, Fritz von Unruh: Rebell und Verkünder (Hannover: Verlag fur Literature und Zeitgeschehen GmbH, 1960), S. 41.

2 Johann Wolfgang Goethe, West-Östlicher Divan, Theatergedichte (Zürich: Artemis Verlag, 1959), S. 303. 
Menschen, deren Schicksal ihn so sehr bewegte, zu warnen. Aber damals haben viele nicht begriffen, wie sie selbst zu der Wendung bei- . tragen können, die die Menschheit nicht nur vor dem Untergang bewah. ren, sondern das Tor zu einex neuen und besseren Welt offnen kann. Diese neue Welt zeigt Fritz von Unruh in seiner Trilogie. Der Weg zur Gestaltung aber fängt schon eher an. Als Kadett demonstriert der Dichter eine gewisse Anerkennung zweierlei Weiten, die im engen Zusaxhmenhand steht mir seinem Pflichtbegriff. Als Offizier exreicht er s. seine innere Wandlung, die ihm vom Patrioten zum Kriegsgegner macht und die zur gleichen Zeit als Stempel seines dichterischen Schaffens gilt: "Als bewunderter Rebell ist Unruh 1912, in unsere Litexatur einge-treten. Und ein Rebell ist auch der Fünfundsiebzigjährige noch." 1 Irn October $1914 \mathrm{schrieb}$ er aus tiefstem Entsetzen und tiefster Verzweiflung seine erste Absage an den Krieg, das dramatische Gedicht "Vor der Entscheidung." Schon hier ahnt er, dass aus dern Weltkrieg eine neue Welt entstehen. werde. Er demonstriert den Bruch mit einer: Pflicht, die dem Menschen Gewalttat und Totschlag zur Pflicht machen kann. Immer wieder fragt er sich: "Warum muss das sein ?" Aus dieser Verzweiflung entwickelt sich sein Aufruf zum Umsturz, der den neuen Kosmos seiner Trilogie einleiten soll.

Das Gedicht nimmt die Trilogie und dessen Ausgang vorweg: In den ersten zwei Teilen beweist Unruh, dass er nicht bloss eine bostehende

1 Rasche, S. 6 
Welt verneinen, sondern mit ernstem Wollen eine neue gestalten will. Diese zwei Teile sind, die Bühnenanweisung sagt es ausdrücklich, an kein Zeitkostüm gebunden. 1 Sie wollen nicht blos bringen, was Abbild der Gegenwart wäre, sondern sie greifen weit über die Zeit hinaus und weisen den Weg in eine ferne Zukunft. In der Trilogie findet der Dich.. ter das Feilmittel der Neugestaltung in der Forderung, das Verháltnis von Mann und Weib neuzuordnen. Das Weib auch in der Ehe zur Durchgeistigung zu fuhren, die Ehe dadurch auf einen neuen und besseren Bodenzu stellen. Hierdurch schafft er automatisch ein besseres Verhältnis von Mensch zu Mensch, das den Frieden in der Welt bewirken soll.

1 Fritz von Unruh, Ein Geschlecht (München: Kurt Wolff Verlag, $1917)$, S. II 
KAPITEL II

\section{DER JUNGE DICHTER UND DIE WEITT}

Fritz Wilhelm von Unruh wurde am 10. Mai 1885 geboren. Ex ist der Sohn des Geveralleutrants Karl von Unruh und der Frau Mathilde, geborene KIetze. Von zehn Geschwistern, fün Brüdern und funf Schwestern, starben zwei in jungen Jahren, während sein Bruder Erich. irn ersten Weltkrieg fiel. 1

Wie alle seine Brüder wurde auch Fritz von Unruh fïr die Offizierslaufbahn bestimmt, ohne jedoch eine Neigung für diesen Beruf zu empfinden. Die Kindheit wax fur ihn zu Ende als er, achtjährig, nach Plon in Holstein auf die Kadettenanstalt geschickt wurde. Davor lagen die sorglos glücklichen Jahre in Berlin mit schönen Erinnerungex an Paraden und Hausbälle der Eltern. Diese glückliche und natürliche Entwicklung wurde in der "Kinderholle", in der Zwangsanstalt des Kadettenkorps, unterbrochen. Hier sammelte er die Einsichten und Erfahrungen, die später in seiner. Dichtung zu umstürzender Erkenntnis und zum Protest geworden sind. Wogegen er sich auflehnte und worunter ex litt waren die Quälereien, die sich schon der Stubenälteste erlau.-

1 Unterhaltung mit Kurt von Unruh, München, März, 1967. 
ben durfte. Es waren die Ungerechtigkeiten der Vorgesetzten, die Verachtung des Menschen, die in dieser Erziehung sich ausdrückte. 1 .

Unter diesen äusserlichen Konfikten entwickelten sich in ihm zwei verschiedene Welten. Einmal hat er, als er noch junger Kadett war, seinen Vater sehr neugierig gefragt: "Vater, wie ist eigentlich der Krieg?" - "Sohn", antwortete er, "wer einen Krieg miterlebt hat, der wunscht keinen zweiten zu sehen." 2 Diese lakonische Antwort schien damals dem Jungen ein grosses Mysteriurn zu enthalten. Was er nicht. begriff, war die Tatsache, dass sein Vater $j_{0}^{a}$ selber in vielen Schlachten heroisch mitgekämpft hatte. Es liess ihm daher keine Ruhe, in Erfahrung zu bringen, warum sein Vater jhn bei seiner doch negativen Einstellung zurn Krieg trotzdern fltr eine militärische Karriere hatte erziehen lassen, mit dem Endziele: Krieg! Warum verbot sein Vater, dem das Cello vielleicht lieber war als der Degen, ihm Musik oder Malerei zu treiben. Sein Vater selbst war doch Musiker. Die Gedanken zweier Welten erschienen, wenn er seinen Vater musizieren hörte. Offt dachte er dann, vielleicht gibt es zwei Welten nebeneinander: Die der Realität und die der Idealität. Aber immer wieder beruhigte er seine Zweifel; indem er an seine Vorfahren dachte. Denn sie alle hatten dieser Welt der Realität gedient, um diese Realität "Staat" immer grösser

1 Fritz von Unruh, Der Sohn des Generals (Nürnberg: Hans Karl. Verlag, 1957), S. 100-1 10。

2 Ibid., S. 168 
und grósser zu gestalten. Aus Familjenrücksichten und Traditionsgefuhl unterdrückte er die Welt der Idealität in sich. Deswegen sah Fritz von. Unruh in seiner Militärerziehung zunächst die notwendige Vorbereitung a f eine erhoffte Heldenlaufbahn. Als Vorbild hatte er seinen Vater und Urgrossvater vor sich. Sein Vater hatte drei Kriege hinter sich gebracht, bei K"onigsgrätz eine österreichische Batterie im Sturm genommen. Das Beispiel seines Urgrossvaters entflammte ihn; denn es war der Urgrossvater, der sich 1806 bei Jena und Auerstädt im Gefecht gegen Napoleon so auszeichnete, dass er mit siebzehn Jahren die höchste Kriegsdekoration, den Pour le Mérite, erhielt. Für den Ruhm seines Vaterlandes zu fallen, erschien dem Dichter als eines Mannes edelste Bestimmung. 1

Erst allmählich und unter schweren inneren Konflikten war der Dichter in Plön von seiner Heldenhoffnung bekehrt worden. Während die robusten Kameraden Rohheit mit Rohheit beantworteten und nach dem Motto:

Brett vorn Kopf!

Stiefel in die Hand!

Mit Gott fur König und Vaterland! 2

allen Zwang und Stumpfsimn hinnahmen, sah sich Fritz von Unruh einer Tortur überliefert, die jeden Tag aufs neue begann. Dass er eines

1 Rasche, S. 25

2. Fritz von Unruh, Reden: Mächtig seid ihr nicht in Waffen (Nürnberg: Hans Kar1 Verlag, 1957), S. 25. 
Tages zum Prinzen-Duzfreund bestimmt worden war, machte sein Los nicht leichter. Denn je näher er denen kam, die über das Volk zu herrschen und ihm als Vorbild zu sein berufen waren, desto weiter entfernte er sich von ihnen.

In dieser Welt der Realität sind es oft kleine Erlebnisse, die dem Menschen die Augen offnen. An einem Maitag steht der Kadett wieder einmal auf dem Schiessstand vor den bekannten Scheiberfiguren: Soldat in blaxex. Uniform, rosa Gesicht und da, wo das Herz ist, der kohlschwarze Zielkreis. Und indem er zielt, verwandelt sich ihm das Scheibengesicht in ein Menschengesicht. Und dann wird ihm plötzlich klar, dass sie ja alle gedrillt wurden, um Gottes Ebenbild zu erschies,sen. 1 Während der darauffolgenden Jahre hat er nie über dieses Er lebnis gesprochen. Denn er fürchtete, als Feigling zu gelten. Und so geriet er in eine Holle lauer Unentschiedenheiten, wo er jede Minute des Tages feige Kompromisse schloss mit Situationen, die in scharfem Widerspruch standen zu seiner Erfahrung auf dem Schiessstand. Er hat, obwohl er manchmal mit dem Gedanken an Selbstmord spielte, die elf Jahre in Plön durchgestanden. Aber er lerrte mehr als im Erziehungsplan vorgesehen war. In diesen Jahren war nicht die Weit der Realität, sondern auch die der Idealität in ihm geformt. Der Gejst, der in ihm lebendig war drängte zur Rebellion und inneren Freiheit.

1 Unruh, Reden ...., S., $121-122$ 
Noch in seinem letzten. Kadetterijahr schrieb Fritz von Unruh sein erstes Theaterstück, den "Jürgen Wullenweber". Das Stück endet mit den. Worten Wullenwebers:

Befreien wollt' ich euch fürs Leben jetzt macht mich frei von euch gebt mir: den Todesstreich. 1

Ein Rebell für die Freiheit war die erste Gestalt, an der sich Unruh dramatisch versuchte. Ein Rebell fur die Freiheit ist der Dichter bis heute geblieben. Denn am 8. Dezember 1966 hat die Liga für Menschenrechte ihm die "Karl von Ossietzki Medaille" verliehen.?

Natürlich hat das frühe Aufbegehren. Unruhs psychologische und ganz private Gründe. Aber es wäre falsch, zu behaupten, dass hier aus der bösen Jugenderfahrung sich ein Komplex gebildet hätte und sich aus ihm wiederum eine Lebenstheorie entwickelte, die nur ihn anging. Das Gegenteil ist der Fall. Was Unruh als Kadett erlebte, erlebten zahllose junge Menschen, und nicht nur im Kadettenkorps. Unruh erkannte, indem er es am eigenen Leibe und an der eigenen Seele erfuhr, dass unter der Militärerziehung die Menschen zu "Gehorchpuppen" gedrillt und dressiert wurden. Er revoltierte gegen den militärischen Pflichtbegriff "du sollst" dem er sein "ich will" unermüdlich entgegenstellte. Die Welt der Idealität schob die der Realität in den. Hintergrund. Der

1 Rasche, S, 28

2 Brief Kurt von Unruhs, vom 5. Februar 1967 aus Roding. 
Riss zwischen seinen militärischen Pflichten und seinen Gewissenspflichten weitete und vertiefte sich immer mehr. Immer unerträglicher wurde der Widerspruch zwischen seinem T.un und seinem eigentAichen Sein und dem, wozu er sich berufen fühlte. Er gehörte in eine andere Welt.

Nach seinen Jahren als Kadett wurde Fritz von Unruh Offizier der kaiserlichen Garde in Berlin. Aber er war ein ungewöhnlicher Offizier. Er lief in die Universität zu Vorlesungen, er mischte sich in the Kreise der Külnstler und des Theaters. Nachts begann er, sich aus Büchern Rat zu holen. Er las Tolstoi, Dante und andere Werke. Wie sich eine Biene aus den verschiedensten Blumen Honig saugt, so holte er sich … aus Büchern den Gedanken, den er in seinem Gewissenskonflikt brauchte. Und da bemerkte er entsetzt, dass alles was er die Soldaten zu Iehren hatte, in schroffern Widerspruch stand zu den Menschheitgedanken, die er zuvor beim Juesen gefunden hatte. 1 Und trotzdem fuhr ex fort, zu drillen und gedrillt zu werden.

Was er in Wirklichkeit noch nicht erreichen konnte, schaffte er in seiner Dichtung: den Bruch mit der "veralteten"Pflicht. In den Jahren 1911 und 1913 schrieb er seine Dramen, "Offiziere" und "Louis Ferdinand, Prinz von Preussen". Durch diese zwei Werkezieht sich der Kampf zwischen Pflicht und Neigung. Dern "du soilst" setzt er sein

1 Rasche, S. 27 
"ich will" entgegen, ohne noch zu einem befriedigenden Ergebnis zu gelangen. Die Lösung fand er erst im zweiten Teil der Trilogie, indem er dem Pflichtbegriff eine neue Form gab. So setzte sich Unruh in * diesen Dramen mit der im Kadettenkorps gedrillten Gehorsamspflicht auseinander; der er die Neigung der eigenen. Personlichkeit entgegenstellte. Hier war der Dichter noch Patriot, die Helden dieser Werke erhofften eine Befreiung ihrer Persönlichkeit vom Zwang durch den Krieg.

1) Dann aber kam dieser Krieg, und sie empfanden nun, dass auch hier nj.cht nur der Einzelpersónlichkeit, sondern der gesamten Menschheit der Untergang drohte. Die Helden starben, aber ihr Tod hatte ... einen Sinn. Denn selbst der Oberst in "Offiziere", der eben noch auf den Ungehorsam wütete, erklärt: "Also es gibt tatsächlich F"älle ... wo es Pflicht eines Offiziers ist, zu handeln auf eigene Verantwortung!"l.

Der Dichter hat die Lósung noch nicht géfunden, deswegen sehen wir diesen Widerstreit zwischen den beiden Pflichten in jeder Dichtung wiederkehren. Aber an der Lösung arbeitete Unruh schon in diesen Dramen. Denn bemerkenswert sind die Rollen, die die Frauen spielen. Sie sind hier die Trägerinnen des Lebensgedankens. 2 Sie wären berufen gewesen, die neue durchgeistigte Ehe zu schaffen... Konnigin Luise

1 Fritz von Unruh, Dramen (Nürnberg, Hans Karl Verlag, 1960 S. 60 .

2 Bernhard Diebold, Anarchie im Drama (Berlin: Heinxich Keller Verlag, 1928), S. 411 
in "Louis Ferdinand" aber klammerte sich an die alten Vorstellungen von Tradition, und Hedwig in "Offiziere" scheiterte, weil ihre Gedanken von ihrem Vater, dem Oberst, beeinflusst worden. waren. Noch

अ stehen die Frauen hier im Hintergrund, aber sie werden endgültig die Lösung der Pflicht bewirken. So enthüllten sich die beiden Paare als Vorstufe von Dietrich und Irene in der Trilogie.

Mit dem Drama "Offiziere" verliess der Dichter cie militärische

* Welt der Realität. Sein Regimentskommandeur stellte ihm ein klares

Ultimatum: wenn das Stück aufgefúhrtwürde, hätte er den Dienst zu quittieren. Die Auffuhrung war ein grosser Erfolg. Damit war für Fritz von Unruh die Entscheidung gefallen. 1 Und doch war es erst ... eine Vorentscheidung. Er ging auf Reisem. denn Preussen war ja nicht die Welt, nicht einmal Deutschland. Und er hatte mit der Uniform noch nicht alles von sich getan, was er abwerfen musste. Zwar enthüllte er sich as Rebell gegen die Mächte, die seinen jungen Willen knebelten, aber ein Gestalter und Schöpfer war er noch nicht. Er blieb zuerst ein Umstürzler. Er war noch zu sehr Kind seines Stammes, zu sehr seiner Tradition und Herkunft verpflichtet, un Gestalter zu sein. Zwar klang die Sehnsucht nach einer. Vollkommeneren Welt durch die Werke, aber neu schaffen konnte er sie nicht. Erst musste er sich selbst gewandelt haben, bevor er eine Welt verwandeln konnte. Seine

1 Wilhelm Geyer, "Fritz von Unruh, Versuch einer Deutung", 4. Heft (Rudolstadt, 1924), S. 9. 
innere Wandlung musste von aussen, durch ein ungewohnliches Ereignis unterstützt werden. Und dieses Ereignis hiess: Krieg.

Noch einmal siegte das Soldatenblut der Farnilie. Er meldete sich Freiwillig, mit dem Gedanken: "Vielleicht ist es meine Pflicht, nun in Wirklichkeit zu erproben was ich bis dahin nur in Gedanken erlebt Fatte". 1 Auch die mysteri"ose Antwort seines Vaters wollte er erproben. Als Patrouillen-Offizier wurde er vom Pferde geschossen, lag

* eine Nacht bewusstlos und ausgeplundert auf einem toten französischen

* Soldaten. Er erfuhr bald, was Krieg aus den Menschen machte. Eines Tages, urn vier Uhr morgens vor Rheims, hatte er eine religiose Vision und aus ihr kam das Gedicht "Das Lamm":

Lamm Gottes, ich sah deinen wehen Blick, Bring Frieden uns und Ruh, Fuhr uns bald in die Himmel der Liebe zurück Und deck die Toten zu. 2

Innerlich war Unruh weit "uber seine patriotischen Helden hinausgewachsen; er entdeckte in der Wirklichkeit des Weltkrieges das Grauen, den Tod, die Verwesung, die Sünde des Herzens und nicht den glorxeichen... Sieg und die Macht. In diesem religiösen Augenblick der Erleuchtung wurde der tatenhungrige Dichter zum Kämpfer für das Leben gegen die Mächte, die das Leben lähmten und unterdrückten. In diesem Augenblick der Kriegserschütterung wusste er plötzlich, dass seine gesamte

1 Unruh, Reden ...; S. 127

2 Alfred Biese, Poesie des Krieges, I (Berlin, 1915), S. 4.9. 
militärische Erziehung falsch gewesen war. Denn er fühlte, dass die Menschen erschaffen worden waren, um die Liebe und Harmonie zu leben, dass wir hier auf Erden da sind, um unser Selbst nach Gottes Ebenbild zu verwandeln! Jetzt weihte der. Dichter sein Selbst dem Kampf flur den hohen Sinn einer neven Welt, in der die Menschen in * Frieden und Ruh leben können. Mit Recht sagte Goldschmidt: "Das * Land der Menschheit fand Unruh erst, als er durch das Leid des Krieges wandelte." l

Der preussische Offizier aus altern Adelsgeschlecht trat heraus, nicht um eine bindungslose Freiheit zu leben und zu propagieren, sondern um neue tiefere Verpflichtungen einzugehen, um eine menschen-... würdigere Verantwortung zu übernehmen. Diese Wandlung vom Patrioten zum Kriegsgegner stellte ihn in die Lage, seine neue Welt zu schaffen. Mehr und mehr aber erkannte er die Notwendigkeit zum Umsturz, der als Vorstufe der neuen Weltgestaltung gelten soll. Den Umsturz stellte er in dem dramatischen Gedicht "Vor der Entscheidung" dar.

1 Rudolf Goldschmidt, "Fritz von Unrule," Dichter und Bühne, (Augsburg, 1921), S. 6. 
KAPITEI, III

\section{DER RUF ZUM UMSTURZ}

Wenn in den eben erwähnten Dramen der Krieg a].s der Menschenretter dargestellt war, so war der Krieg in "Vor der Entscheidung" dex Menschenvernichter. Dieses Gedicht, das er im Oktober 1914 schrieb, prallte schon vor der Grausamkeit zurück, die im Krieg Gebot wurde, verkundete schon den Umsturz und ahnte schon, dass aus dem Weltkrieg eine neue Welt entstehen k"onnte.

W"ahrend es in der Heimat Dichter gab, die in patriotischer Kriegs Iyrik, in Hass - und Siegesgesängen schwelgten, schrieb an der Front Fritz von Unruh sich das Grauen von dex Seele. Denn die Ereignisse im Felde hinterliessen bei dem feinfuhhligen Dichter einen besonders starken Eindruck. "Er war", so berichtete ein Kamerad von ihm, "von allem Erlebten und Gehörten sehr viel tiefer ergriffen als wir anderen." Was er in dern Gedicht zu sagen hatte, legte er vielen Gestalten in den Mund, raffte er in kurzen Reimszenen zusarnmen. Unruh selbst trat als Ulan auf.

Voller Begeisterung stürmt der Ulan, ideologisch wohl vorbereitet,

1 Brief des Hauptmanns G. Schelle vom 9. April 1924 an Kurt von Unruh. 
in den Krieg. Aber ali die gepriesenen Ideale - Volk, Ruhm, Vaterland, Ehre - sieht er zerbrochen, entlarvt, zunichte geworden vor der Unmenschlichkeit des Krieges. Wer befiehlt ihm zu morden? Er schüttert fragt der Uláa:

\section{Welche Wahrheit leuchtet ? \\ Kann dieses Gemordes dein Wille sein ? - Ist es dein Wille ? 1}

Was hat Pflicht aus diesen Leuten gemacht !. Unter solchen Eindrüuken legt er sich die entscheidende Frage vor, was denn in diesem Falle elgentilich Pflicht sei. Der Freiwillige kennt des Ulans Seelenkämpfe nicht; er fuhrt freudig und inbedingt aus, was ihm befohlen wird und hofft, dass es fur des Vaterlandes Macht und Grosse von Segen sein werde. Für den Ulan dagegen scheint es unmöglich, "das in Blut und Waffen ein Volk sich seinen reinsten Kelch erringt. "2 Unmöglich kann es Gottes. Wille sein, dass die Menschen sich gegenseitig ermorden. Auch kann die Pflicht es nicht wollen, dass er weiter mitkämpft. Denn wo bleibt bei dieser Zwangspflicht die Tat aus freiem Willen zur Selbstbesiegurg? Da zeigt ihm in Traumvision der Geist Shakespeares neue Wege. Den Krieg des Friedens gilt es anzutreten. Er soll das Kreuz wieder aufheben, den Stab, der den Menschen erlösen wird. Er nimmt das erschossene Kreuz als mahnendes Symbol auf. Da kommt

1 Eritz von Unruh, Vor der Entscheidung (Berlin, Erich Reiss Verlag, 1919), S. 38

2 Ibid., S. 26. 
ihm das Gesicht einer neuen Zeit: "Mutterland soll aus dem Krieg sich heben, frühlingsjung und stark vor Werdeglück." 1

Begeistert von dieser Vision fuhlt der Ulan sich jetzt reif, der Erscheinung Kleist, dem Schatten seines alten Icḥs zu begegnen. Dem Ulan wird es zur Gewissheit, dass "S"undensaat und Waffensang"2 vergehen müssen. Dies verteidigt er auch gegenüber Kleist, dessen Hassgebot er nicht befolgen kann. Er will dem Volkerhass Finhalt gebieten und weltumfassende Liebe an seine Stelle setzer. Der Hassänger Kleist tritt dem Ulan entgegen:

\section{Brennend vor Wut und Lust Schlüg meine Z̈̈uhne ich Tief in die welsche Brust, Liebe zerstampfte ich. 3}

Andererseits versichert Kleist, dass auch in ihm die I-iebe ist; er hasst den Feind, weil er Deutschland liebt. Er sei ein Teil seines Heimatlandes. Wenn er seinem Vaterland den Rücken wende und von menschlicher Brüderschaft träume, dann werde er wie der Ulan "ein Bettler ohne Kraft". 4 Doch der Ulan, der sein Gewehr als Instrument der Holle weggeworfen hat, findet eine ganz andere Antwort auf seine Frage nach dem Sinn des Krieges. Er setzt an die Stelle des starren, der Staatsräson unterworfenen Pflichtbegriffe, die Pflicht zur Liebe, die keine Grenzen kennt, sondern die grosse Bruderschaft, die Mensch -
1 Ibid., S. 82
3 Ibid., S. 104
2 Ibid., S. 62
4 Ibid., S. 104 
heit bedeutet.

Die Liebe, die der Dichter sich hier vorstellt, kann nur gedeihen, wenn sie ungeteilt und allumfassend ist und wenn ihre Antithese, die Macht, gestürzt wird. Wenn die Liebe - so antwortet der Ulan der Frscheinung Kleist - sich bloss auf eine bestimmte Gruppe richtet, wie es bisher gewesen ist, dann ist sie nur die Kehrseite des Macht.. triebes. Die Macht gewinnt nur im Verhältnis zur Chnmacht Bedeutung. Ein Mensch oder ein Volk ist nur dann rnächtig, wenn andere Menschen oder Volker machtlos sind. So ist die Macht die Ursache aller Grausamkeit und Unzufriedenheit. Die Liebe soll ungeteilt sein. Das ist das neue Gesetz, nach dem der Ulan sucht, ein dynamisches Gesetz. Es ist nicht mehr die von Tradition, sondem die aus Liebe gestaltete Pflicht:

Spannen, spannen um die Firde Weil ich meiner Liebe Flügel... Bis der Sonne tiefster Sinn Aufbricht aus Gesetzessäule. 1

Hier symbolisiert Unruh die Sonne als die Schöpferin. Sie ist wie eine neue Realität in dem Chaos des Krieges, die aus den Gesetzesäulen ausbrechen soll. "Der Sonne tiefster Sinn" ist die Erschaffung und Erhöhung des Lebens. 2

Die Formulierung der neuen Pflicht aber setzt eine "Anderung der

1 Ibid., S. 1.05

2 Unruh, Reden...., s. 131. 
Menschen selbst voraus:

Eh' du nicht mit heil'ger Kraft

In dein Innerstes gedrungen,

Dich zerbrochen, dich bezwungen

Und dich urn und urn geschafft -

Wird nicht deiner Seele Klang

Rein im Weltall schwingen.

Stèrben soll: alles, was die Menschen hinfuhrte zu diesem Krieg. Alles, was sich zwischen die Menschen und die Sonne stelle, müsse sterben, sei es die aussere Macht des Staates, sei es der Feind in uns selbst. Und werden soll das Verhältnis von Mensch zu Mensch, die Ijiebe und Bruderschaft, die den Frieden in der neuen Welt mit sich bringen soll. "Es gibt keine andere Arche, Euch aus der nahenden Sintflut zu heben als Euer eigenes Herz". 2 Das Herz soll das Zentrum des Werdens sein. In ihm liegt diè Kraft, Welten zu besjegen. Das Herz, in unlöslicher Verbindung mit dem Geist, müse aus dem Chaos den Kosmos bilden. Zu dem Zweck bedürfe das Herz in jedem Menschen der inneren Liebe, die in der Absage an alle menschlichen Laster besteht. Erst wenn die Menschen diese Liebe, diese Wahrheit besässen, könn-.. ten sie in die "Freude schópferischen Daseins"3 gelangen. Denn "in dir berührt sich Holl und Himmelreich; aus dir entrollt die Schoopfung

1 Unruh, Vor der Entscheidung, S. 107.

2 Unruh, Reden ..., S. 16 .

3 Unruh, Vor der Entscheidung, S. I14. 
jeden Glanz". 1 Dann seien sie reif zum Werden, und es könue sich dej: Geist mit dem Herzen zu dem neuen Bunde zusammenstellen.

Reif sein, reif der höchsten Liebe, Die uns erst zu Menschen macht.

Fordert aller Gieren Triebe!

Wollt ihr, sei diesés Werk voljbracht ! ${ }^{2}$

Aber weit scheint Unruh diesem Ziel noch entfernt zu sein. Zwar bleibt dieses Werden nur noch eine Frormulierung, keine vollzogene Wirklichkeit. Aber der Dichter was überzeugt, dass die Menschen die Verluste und die Leiden, die der Krieg ihnen auferlegte, nicht zu ertragen vermöchten, ohne sich bis ins Tiefste zu ändern. Er, wie viele Expressionisten "uberhaupt, hat den starken Glauben an das letzte Ereignis: die Bekehrung, die Wandlung, die das Ende der Geschichte einläuten und die Vollkornmenheit bringen würde. ${ }^{3}$

Wie eine Bestätigung von Unruhs Vision, dass der Mensch bereut und sein Verhalten ändert, erschien Ende 1917 Ernst Tollers "Die Wandlung". Friedrich, der Held des Dramas, meldet sich bei Kriegs ausbruch freiwillig zum Frontdienst. Auch er möchte beweisen, dass er dazugehört. Für Toller - Friedrich besitzt der Krieg, wie bei Unruh - Ulan, die Eigenschaften, die später die Revolution gegen dèn

1 J.bid., S. 116

2 Ibicl. s S. 133

3 Otto Mann, Geschichte des deutschen Dramas (Stuttgart: Alfred Kröner Verlag, 1963, S. 557. 
Krieg erhalten wird. Der Held malt sich den Krieg als die Dämmerung nationaler F3ruderschaft aus, in dern sich alle Probleme l'osen und seine Isolierung für immer ein Ende haben wird.

Auf dem Schlachtfeld kam Ernst Toller, genau wie Unruh, zur expressionistischen Vorstellung vom Einssein der Menschheit. Toller berichtet grauenvolle Schützengrabenerlebnisse, die seine patriotische Begeisterung schwer erschütterten. Der Anblick eines Verwundeten, der drei Tage und Nächte im Stacheldraht hing und unablässig um Hilfe schrie, trug zu Tollers. Wandlung bei:

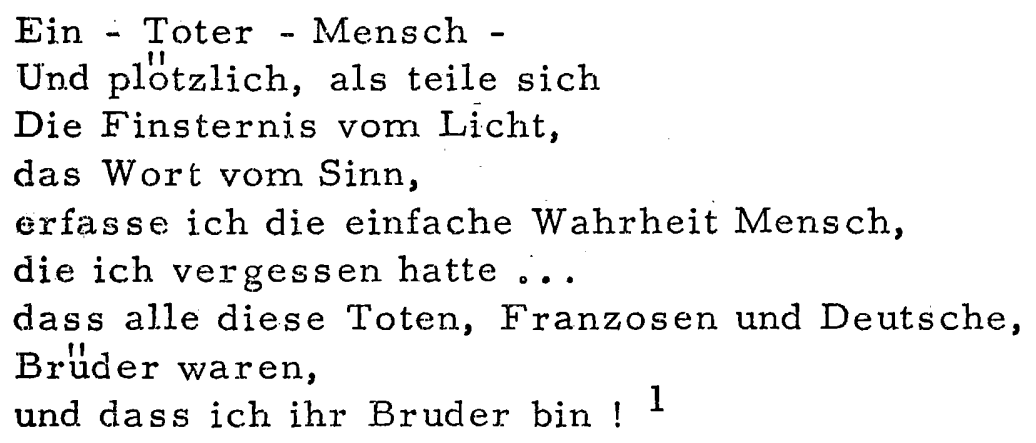

Die Wiedergeburt des Einzelnen ist die Betonung der expressionistischen Revolution. Auch fur Unruh ist diese Wiedergeburt der Schlússel zur neuen Welt. Nur eine innere Wandlung kann den neuen Pflichtbegriff verwirklichen, kann die Welt neugestalten, kann den Vernichtungs geist in den Menschen zum ewigen Friedensgeist verwandeln.

Die Sehnsucht nach der neuen Pflicht zur Liebe ist des Dichters Ruf zum Umsturz; der als Anfang der Entwicklung der neuen Welt gel-

1 Ernst Toller, Eine Jugend in Deutschland (Berlin, Erich Reiss Verlag, 1922), S. 75, 76. 
ten soll. Schon in "Vor der Entscheidung" macht sich ein neues Werden, als Folge der Liebe - Predigt des Ulans, fühlbar. In den Herzen auch des einfachsten Soldaten spüren diese so ganz verschiedenen Menschen eine bessere Zukunft. Ihr Zeichen ist: Glaube an die ewige Kraft der Liebe, auch aus Tod und Zerstörung wieder Leben zu schaffen. Dieser einfache Glaube trägt und beschwingt sie. Jeder fühlt sei ne Verantwortung fur: Tausende in der Visjon des Aufbaus nach der Zerstörung. Jeder weiss, dass der Weg durch den Krieg sein persönlicher Opfergang fur die Zukunft sein kann. Es ist keine Sicherheit, nur ein Glaube, aber der ist stark genug, sie über alle Sinnlosigkeit hinwegzutragen:

Ob wir siegen, ob wir sterben, Längst entschieden ist die Schlacht!

Wir sind neuer Gnade Erben, Sind die F'ackeln aller Nacht ! 1

Aus der tiefen Verbundenheit mit der Liebe als Element enthüllt sich den Gestalten dieses Gedichtes der Sinn des Krieges. Diese Unerschütterlichkeit triumphiert über die furchtbar weitergehende Autorität des Krieges, denn ihr gläubiges Gefuthl ist die Eigenschaft einer neuen Zukunft.

Mit der Formulierung dieses revolutionären Erkenntnisses hat der Ulan - Unruh seinen Wegweiser zur Tat eines Ums turzes gefunden. Er ruft die jungen Soldaten zu einem Kampf auf, nicht gegen den. Feind,

1 Unruh, Vor der Entscheidung, S. 104. 
sondern gegen die ejgenen Herrscher, die sie in Mord und Tod geschickt haben:

Junges Volk auf. allen Wagen:

kommt, wir wollen Burgen brechen. 1

Und in Unisimo antworten sie:

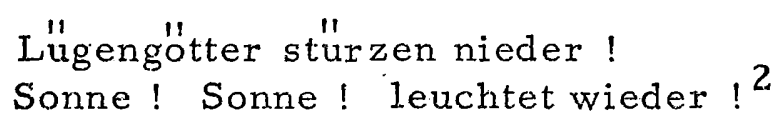

Die Ulanengestalt Fritz von Unruhs ist Träger einer Revolution des Weltgeistes, die eine Entscheidung der Welt einleitet. Ein "Seelensturm der Frde $^{\prime 3}$ ist entfacht, der mit seinem Schopfungswort "es wer de" die Jugend aufruft zux grossen Verwandlung, zum Umsturz.

Die Entwicklungslinie im Schaffen des Dichters läuft von dem Gedicht "Vor der Entscheidung" zu der Trilogie "Ein Geschlecht". Immer mehr festigt sich in Unruh die Erkenntnis, dass der Krieg alle Werte umstürzen müsse, dass hinter der zivilisierten Zeitmaske das eigentliche Weltgesicht auftauchte. Er spürte, dass das Chaos um des Men. schen und des Weltsinnes willen langsam zu einem Kosmos neuer Werte erschaffen werden müsse. Dieses Schaffen offenbart er in seiner Trilogie.

1 Ibid., S. 140

2 Ibid.

3 Ibid. 
KAPITEI IV

\section{VOM CHAOS ZU EINEM NEUEN KOSMOS}

In dem ersten Tejl der Trilogie verwandelt sich der Umsturz in Chaos. Die Menschen dieses Chaos' sind Urmenschen, und ihr Reich ist der Trieb. Die Menschenwelt ist dargestellt duxch ein paar mythische Gestalten. Die Landschaft ist der Holzwald eines Massenfriedhofs. Das Kriegsgetummel spukt herein, ist aber für das Schauspiel, nicht wie in "Vor der Entscheidung"; an sich fast nebensächlich und nur arn Anfang der Exposition wichtig. Die gewaltige Erschütterung legt die Tragik der Welt bloss: das Auseinanderfallen der Einheit, die Selbst vernichtung von Kräften im Karnpf gegen ihren Ursprung. Der Kampf, der den Ursprung des Lebens, die Mutter des Iuebens bedroht. Dieser Kampf wird in der: Tragódie "Ein Geschlecht" entschieden." 1

A. Das Chaos in "Ein Geschlecht"

Das aus einem Aufzug bestehende Stück spielt während der Nacht auf einem alten Kirchhof auf einem Bergesgipfel. Mutter, Tochter und jungster Sohn begraber einen in der Schlacht gefallenen Sohn. Zwei

1 Julius Fetersen, "Fritz von Unxuh", Das literaxische Echo, XX (Berlin: Egon Fleischel Verlag, 1.917), S. 1296. 
weitere Sohne sind zum Tode verurteilt; der älteste, weil er Weiber schändete, der andere, weil er aus Feigheit den Gehorsam versagte.

Beide werden gefesselt von den Soldaten herangeführt. Der jüngste Sohn soll das Urteil vollstrecken, er soll seine Brüder töten. Doch er schrickt davor zurück. Er kann es nicht tun, da er nie getötet hat. Die Soldaten ziehen wieder mit den Leuten ins Kampftal, ahnend, dass sich das Fluchgeschlecht selbst vernichte. Den jungsten Sohn schleppen sie Fit, damit er in der Schlacht gehärtet werde.

t. So bleiben Mutter, Tochter und die Verurteilten allein auf dem alten Kirchhof. Der älteste Sohn hatte für den Staat gemordet. Er fehlte, weil eine ungezügelte Kraft ihn befiel, die seine Triebe entfesselte. Entschlossen hat er sich von aller Überlieferung losgesagt und will gegen den Massenwahn kämpfen. Als die Ursache allen Übels sieht er seine Mutter an. Dem sie gebiert nach seiner Ansicht nur den Tod. Auch die Schwester stimmt zu. Beide wollen die Mutter ermorden. Der älteste Sohn wirft seine Ketten ab und stürzt sich mit einem Fluch auf seine Mutter, in den 'Tod.

Die Mutter sieht jetzt, was der Krieg aus ihren Kindern gemacht hat. Kraft gibt ihr die Erde, in die sie sich eirgräbt. Unerbittlich verflucht sie ihre Kinder und kümmert sich nicht um ihren. Tod. Jedoch dieses Geschlecht ist nicht ganz dem. Untergang geweiht. Wohl stirbt auch die Mutter, niedergestossen von dem zweiten Soldatenführer. Aber sie hat dem Führer zuvor den Stab entrissen und als Symbol der 
Macht.über die Erde geschwingen. Sie verkündet, dass eine neue Welt kommen wird.

Máchtig geben die ersten Verse das Thema an: "Unseliges Weib, gesegnet und verflucht". 1 Hier offenbart sich das Geheirnnis der Welt inder Gestalt der. Mutter: das Geheimnis des Werdens in seinem Segen 浻und Fluch. Gesegnet in dern Sinne, da sie die Gebärerin des Lebens ist, verflucht, da sich aus ihr ein Mórdergeschlecht entwickelt hat. "Wer fasst Natur, die solchen Zwiespalt schuf", 2 sagt der Soldatenf"uhrer, der die zwei Sohne mitschleppt. Schon am Anfang wüten die Kinder gegen äie Mutter. Denn sie giesst mit ihrem Blut nicht nur Tugend in die Adern jhrer Nachkommenschaft, wie in ihren jüngsten Sohn, sondern auch Mordsinn, Tierwut, und Feigheit, wie in den altesten Sohn und die Schwester.

Die Mutter steigert sich zur mythischen Gestalt. Denn hier kämpft die Mutter alles Lebens, hier kämpft die Welt um ihren Sinn. Als ihr jüngster Sohn in die Schlacht geführt wird, da begleiten ihre Worte eine allessagende Bewegung: sie streichelt den Boden, von dem ihr Sohn wegschreitet. Sie sieht den Untergang und die Vernichtung einer Welt um sich und glaubt doch an den.Sinn des Lebens. Sie weiss, dass alles Sein auch Sinn hat:

1 Unruh, Ein Geschlecht, S. 9.

2 Ibid. 
$O$ I and vom Wachsturn ewiger Kraft bewegt, du gibst den Schwangern ihre Monde bis sie sich beugen Neues zu gebären... Verhilf auch mir zu neuem Blut! 1

Aber dieser Wunsch bileibt noch unerfulltt. Der. Kampf gegen ihre Kinder wühlt diese Frau auf. Zuerst, beschwört sie ihre Kinder mit der Bitte um Kindesliebe, mit dem Gedanken an ihre Mutterschaft. Dem "ltesten Sohn hält sie die W"ürde des Vaters und ihre Liebe für ihn entgegen. Er aber sagt:

Dás sagst du mir, der jeden leichten Hauch belastet fühlt von Ur - und Urvätern ? . . . Dann hobt Ihr uns den Vater auf den "Sockel, und jedes Wort der Kinderstube wies, den Urtrotz in mir weckend, streng auf ihn, bis ich genährt am Zweifel, kraftentschlossen dieses Vaterbild, das Gott geglichen, stürzte. 2

Der Tochter predigt sie die Seligkeit der Mutterschaft als die Erfullung des Weibturns, aber diese stöst sie weg:

Mich widert dieses Lächeln der Exfahrung, mit dem du mich noch fester an dich drückst, ... Wie ein Stück Fleisch am Markttag liegst du feil ! 3

Die Mutter steht den Handlungen ihrer Kinder machtlos gegenüber:

Wo bleibst du, Gatte, der Du einst gewacht, dass mich nichts Hässliches ber"uhren konnte
Muss dieses Herz denn alle Gifte schlucken ?

Seinen Geist, den Geist des Vergangenen, will sie beschwören, um den

1 Ibid., S. 21

2 Ibid., S. 33
3 Ibid, s. 42,43

4 Ibid., S. 33 
Kampf ihrer Kinder bestehen zu können.

Mit Absicht hat der Dichtex die Frau ohne ihren Gemahl dargestellt.

Denn fur Unruh bedeutet der Mann als der Zeugende die formende Kraft,

die im Mütterlich-Weiblichen das Leben sucht und findet und in der lie.. benden Einheit die Lebenstotalität und Unsterblichkeit erkennt. Nur

der Mann kann ihre Kraft in Gestaltung auswirken. Erst arn Ende der

* Tragödie sieht sie in jüngsten Sohn den Gestalter ihrer Kraft. 1

Mit allen Tönen ihrer Mutterliebe verteidigt sie sich, weil die

Kinder unablässig ihre Gefühle schänden. Der älteste Sohn will in einem Ansturm die Welt zerreissen, um ihren letzten Sinn zu fassen.

Die Mutter aber glaubt an die Gesetze der Natur, sie kennt den stillen.

Zwang im Wachstum alles Lebendigen. Sie will noch nicht glauben an den Untergang der Schöpfung:

Wir Multter kennen diese harten Stunden; wenn wir schon leise Wechselrede hatten mit dem, was stetig schweigsam in uns wächst. 2

Das ist ihr frommer Glaube an die Lebendigkeit als der Sch"opferkraft. Nur aus diesem Glauben gewinnt sie die Kraft zum Kampf mit ihrem Schicksal, das ihr von den eigenen Kindern bereitetwird. Dieser Glaube, versetzt sie später in die Lage, die sinnlose Rebelilion des ältesten Sohnes zu einer konsturktiven Revolution zu verwandeln.

1 Diebold, Anarchie im Drama, s. 420.

2 Unruh, Ein Geschlechts S. 40. 
Aber erst scheint es in eine Niederlage auszumünden: "O alle Erdenmütter, flucht mir nicht: In mir bricht jeder Widerstand zusammen." 1 Und dann richtet sie die grosse Frage an das Leben:

Was ich jetzt tu heisst an die Erde klopfen,

Hier liege ich und beschwóre ohne Formeln das Herz, das hinter aller Schöpfung schlägt. 2

Aber die Beschwörung bleibt olne Antwort. Sie ist noch nicht reif für die letzte Firkenntnis. Sie kann noch nicht fassen, dass alles Geborene den $M$ utterth wieder genommen wird, dass diese Tierwelt uniergehen muss, bevor eine neue Welt gestaltet werden kann. Die Bitte um Kindesliebe "andert sich jetzt in Worte voll Hass: "Hätt' ich euch nur, als Thr nach Brüsten schriet, am Stein zerschmettert, undankbare Brut." 3 Ihr Wortkampf scheint hier seinen höchsten Punkt zu erreichen. Jedoch wird der Vernichtungsgeist ihser Kinder ihr zu mächtig und sie schreit mit ganz neuer Kraft die unmenschlichen Worte der Bezwingung:

Ich bin es müde, angeklagt zu stehen!

Was wisst ihr von der Mutter! dass sie schwach

und Eure Torheit schützen wollte! Seht, nun sagt der Mutter..Schatten, den ich rief, und spricht ein ernstes, hartes Wort mit mir:

Sagt: hält der Fels dieQuelle vor dem Sturz ?

Der Zweig die Blute, eh sie fallt ? 4

Sie berührt die Erde mit iłren Händen, um auf diese Weise die Erkenntnis des Lebens fassen zu können. Aus dem mütterlichen Element der

1 Ibid.. S. 23

2 Ibid., S. 24
3 Jbid., S. 51

4 Ibid. 
Erde scheint sie endlich die entscheidende Kraft zu ziehen: ihr eigenes und ihrer Kinder Schicksal zu bejahen. Hier liegt ihre scheinbare Niederlage, die ihr Richtung gibt und die ihr Herz wie eine Sonne hell. erf'tillt::

Nur zu: es fielen in der Zeiten Sturm schon. mwhe als $\mathrm{Ihr}$ und ich Es soll geschehen! !

* Hiermit ist der H"hepunkt der Tragódie exreicht. Die Mutter sucht nirgendwo mehr Schutz und Hilfe. Sie bejaht die Vernichtung dieses Geschlechtes und nimmt so das Schicksal de? Welt in seiner Grösse in sich auf: das Leben und den Tod. Auch in ihr vollzieht sich jetzt das Stirb und Werde. Erst jetzt erkennt sie, dass alles Geborene dem Tod und der Vernichtung anheimfallen muss, dass die alten vaterländischen Ideale fallen müssen, um der neuen Unendlichkeit des Lebens willen. Denn das ist der Rythmus der Welt: Stirb und Werde.

Aufgegeben von der Mutter gehen die Kinder nun ihrem Schicksal entgegen. Der Wortfuhrer des Karnpfes gegen die Mutter ist der "̈lteste Sohn. In ihm hat dex Krieg die Entfesselung aller Kräfte zum Zerstórungswerk bewirkt. Sein Werk will nur Vernichtung sein; und zwar Vernichtung dieser Welt, die das eine Verbrechen bestraft und das andere belohnt. Er fühlt, dass er an einem Ereignis, dem Kriege, teilhat. Man sagt ihm, ex soll, er düfe, ja ex músse in Interesse seines Vaterlandes töten. Er sieht in diesem Befehl eine Genehmigung zum

\section{Ibid。}


Ausleben jedes Triebes:

Doch ich, im Schrei verscheuchten Weibervolks.

Pack mir, ein Blitz, die Widerspenstigste und zwar schon in Gelock der Hoffnung ...

da schlug man mich wie ein Stúck Rindfleisch nieder!

Die gleiche Macht, die mich wie Wunder ehrte, als ich für sie im Blut des Feindes gewatet ! ].

Er wird verurteilt, weil ex nicht versteht, dass im Kampf von Masse gegen Masse das Gebot "du sollst nicht töten" aufgehoben wird, aber dass die Gesetze der Sitte von Mensch zu Mensch aufrecht erhalten bleiben sollen. Er lehnt sich gegen, Tradition und Autorität auf. Was soll Gesetz! Was kümmert es ihn! Zum Symbol dessen lässt ihn der Dichter die Hand in begehrlicher Lust nach der Schwester ausstrecken. 2 Sein Denken ist zu primitiv, um den Ünterschied zwischen Gesetz fur Masse und Gesetz fur Individuum zu verstehen:

Erst reisst man uns auf sonnennahe Gipfel, und hat sich unste Brust dem Tal entwöhnt, dass sie sein Bauerr.joch nicht mehr erträgt, sticht man uns mit Gesetzen durch das Herz. 3

Sein zivilisiertes Menschentum falllt im Kriegsdunst von ihm ab; und ex verwandelt sich zurück zum Tier. Der Mensch gehöt wieder der Urnorm des Triebes. Mit drokendem Protest schreit der "alteste Sohn in den kahlen Raum des Chaos sein Bekenntnis zu eigener Kraft: "Içh

1 lbid., S. 20.

2 Petersen, S. 1297

3 Unruh, Ein Geschlecht, S. 21, 22 


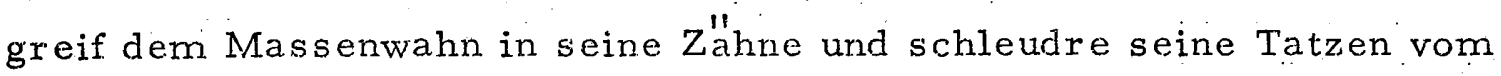
Genick"! 1 As dem chaotischen Zussammenbruch aller Normen findet er ein neues Gesetz: Das Gesetz des Blutes.

Sein Dunst umschwält a uch die Tochter. Auch sie fühlt die Glückseligkeit, sich ausleben, einzig dem Trieb der blutigen Leidenschaft gehorchen zu dürfen. Inzest zwischen den Geschwistern werden elementare Selbstverständlichkeiten.

Du bist es ! Unbegrenztex, Himrnlischer ! nach dem ich mich in heisser Heimlichkeit 2 urtoller sehnte, als die Nacht nach Licht ! 2

flüstert die Tochter ihrem Bruder zu.

Wie der älteste Sohn schrickt auch sie nicht zurück, die Mutter zu ermorden. "Erwürgen dieses Weib", schreit sie. Der Dichter lässt die Stimmen der Geschwister sich nicht nur gegen die Mutter erheben, sondern auch gegen das Prinzip der Welt. Der Wehruf "warum gabst du uns Leben !" 3 wird zum Hassruf gegen die Unerbittlichkeit des Werdens:

O Mutter, Weiber:

Ihr tragt das Grab in eurem feuchten Schoss;

Was ihr gebärt, ist Tod und nichts als Tod! 4

Alle Fragen nach dem Sinn des Lebens enden mit der Rückkehr zur Erde, aus der der Mensch stammt. Der älteste Sohn stürzt von der Kirch-

I

Ibid. , S. 2.3

2 Ibid., S, 21
3 Irid., S. 48

4 Ibid. S. 51 
hofsmauer ins Grab hinab. Noch seine letzten Worte sind eine Anklage gegen die Welt, die ihn zum Verbrecher gemacht hat: "Fluch Dir, der ich gedient und zum Werkzeug war !"l Selbst sein Vernichtungsgeist war im Dienst der Welt. Er trägt das Schicksal der grossen Weltver brecher', die den Lauf der Dinge immer wieder in Bewegung bringen und zu neuer Gestaltung aufrutteln. Sein Ende ist dex Tod, der Sinn seines Schicksals aber ist Anstoss zu einem neven Werden. Aus dem Kriegserlebris schuf er ein Chaos, das ihn selbst verschlingt. Aber aus diesern Chaos wird sich neue Gestaltung entringen. Das ist der Sinn der Mutterworte an der Leiche ihres Sohnes:

Es hat sich ausgerast?

Die Felsen, die du sprengtest, schlugen Dich und tun wie fallendes Ger"ll im Sturz schon ihre Wirkung. Seltsam wird es Tag -, als bliese neuer Odem in die Brust ! 2

Der Sonnenaufgang ist zugleich der Anbruch einer neuen, geborenen W elt.

In jungern Morgen dampfend steht hell, wohin ich seh, in weiter Welt des Wachstums nillchtiger Bau um uns und wächst. 3

Die Tochter verneint die Gluckseligkeit der Mutterschaft. Sie macht sich unfruchtbar, da sie kein Tiergeschlecht gebären will. Auch fur sie gibt es zur Zeit keine bessere Zukunft als: "Ich suche mir ein

1 Ibid., S. 55

2 Ibid., S. 55

3 Ibid., S. 56. 
Dickicht, wo ich ende !" 1 Erstam Ende des zweiten Teils der Trilogie findet sie den wahren Sinn des Lebens.

Aus diesem Chaos kommt die Mutter zum letzten Mal as eine riesenhafte Figur hervor. In diese Stimmung, in der die Wut der Zerstórung sich erschöpft hat, hört man den Lärm anmarschierender Truppen. Es folgt eine Stunde der Entscheidung im Kampf zwischen der Mutter und dem Soldatenführer. In diesem Kampf siegt die Mutter. Wunderbar ist ihre Haltung dem toten Sohn gegenüber, wenn man seine Leiche unwürdig behandeln will: "Rührt nicht an Blut, es ist geheimnisvoll wie alles andere für die Welt vergossen " $^{2}$ Wenn sie dann mit dern Soldatenf"uhrer um den F'uhhrerstab ringt, so geht dieses Ringen um die Weltherrschaft: "Bei mir ! Bei mir die Macht der Welt !" ${ }^{3}$ Über alle Häupter wachsend, grüsst sie in erneuter Lebensglut den Tag der Zukunft:

O Mutterleib, o Leib, so wild verflucht und aller Greuel tiefster Anlass erst, Du sollst das Herz im Bau des Weltalls werden und ein Geschlecht aus Deiner Wonne bilden. 4

Als Verkünder der neuen Welt schleudert sie jetzt den Soldatenführer den Widersinn von Krieg, Machtdienst und Zertrümmerung entgegen und flallt unter seinen Streichen auf den Totenhügel. Aber ihr letzter Wort lebt; das "du sollst" wird durch die "Wonne", in dem die Welt ihr

1 Ibid., S. 66

2 Ibid., S. 60
3 Ibid., S. 61

4 Itrid., S. 65. 
Gleichgewicht finden wird, aufgehoben. Hier sammelt die Mutter alle Triebe, Leidenschaften, Wahnsinne dex Kinder in sich. Mit der Erde sich verleibend vermag sie ihrer Kinder We sen in sich aufzunehmen, Sohn und Tochter zu bezwingen und Gebärerin einer neuen Welt zu werden.

Das ist das Testament der Mutter; aus ihrem Herzblut wird sich die Welt erneuern, sich zu anderen Formen gestalten. Das Erbe dieser mütterlichen Kraft ist der jungste Sohn. Er wird der Vollbringer der Botschaft wom Mutterherzen. So trägt er die aus dem Herzen geborene Revolution ins Tal hinunter:

O Mutterhauch, von dir geschmolzen, rollte die Lawine auf die Kasernen der Gewalt hinab... (zu Kameraden) Steht ihr entsetzt?" Kommt, stürmend Licht reisst uns mit fort; zu Dir, zu Dir, o Mutter "1

Revolution wälzt er mit der Lawine seiner jungen Truppen hinab auf die Kasernen der Gewalt, die noch so festgefugt den Platz umarmen. "Platz" der zweite Teil der Trilogie, ist die Festung der Macht und Gewalt.

Der Tod der Mutter hat auch den Soldatenfthrer ergriffen. Den Mantel der Gewalt wirft er von sich und folgt dem jüngsten Sohn:

Herunter mit dem Tuch der Schrecken ! Ich geb es hin! Die Sonne mög' es bleichen! 2

Das Buch trägt auf seiner letzten Seite die Daten: "Im Felde begon-

1 Ibid., S. 67

2 Ibid. S. 69. 
nen, Sommer 1915 - beendet Herbst 1916." Im Sattel oder in den. Schützengräben würde die Dichtung im Fieberrausch des erlebten Grâens geschrieben. Der überreizte Seelenzustand trägt zur Erklärung der Leidenschaftlichkeit bei, mit der dieser Aufschrei der Menschheit hervorbricht. Aber selbst an den Grenzen des Äussersten verliert die entfesselte Kraft sich nicht in verzerrte Masslosigkeit; uber das Chaos herrschtein sicherer Wille, der die Gewalten zu bändigen und aus dem Chaos efne Ordnung zu schaffen weiss.

Chaos wollte der Dichter und Chaos fand er im Pathos des gesteigerten Wortes. Julius Bab fragt sich, "ob diese mit unendlichen Bildern fieberhaft "uberfullte Sprache ein Ausdruck dichterischer Krafi ist". 1 Aber das Ziel des Dichters fordert eine pathetische Sprache. Die. Welt will er umstürzen, damit er eine neue gestalten kann. Seine Sprache ist deklamatorisch, pathetisch und aufgeregt. Das Tempo ist überall das gleiche. Eilig und stüzend, ein Ausbruch der Leidenschaft nur das wesentliche erraffend. In den Versen ist uberall zu empfinden, dass die Menschen aus innerster Notigung reden und immer nur das, was ihnen zu sagen unbedingt notwendig erscheint. Aber der Rythmus fugt sich dem Dichter, der das Jambenmetrum aus innerer Bewegtheit skandiert. Unruh steht zur Sprache seiner Verse wie ein Dirigent zu seinem Orchester. Man siekt die Bewegung des Taktstocks vor dem

1 Julius Bab, Der Wille zum Drama: Deutsches Dramenjahr 1911 1918 (Berlin: Oesterfeld und Co., 1919), S. 273. 
Klang. Seltsam ist auch der fortwährende Wechsel. Jeden Ausdruck fltgt Unruh triebhaft; Verse und Strophen bald von fliessender Weichheit, bald von stürmender Raserei in verhältnismässiger Ruhe oder wildem Sichüberschlagen. Die Tragódie hat den Rythmus des Aufklangs und des Ablklangs. Aber die Kurve biegt oft aus. Zu häufig ballen sich die Tonmassen nach geringem Anlauf wieder zu Gipfeln, statt dass aus breiten Tälern sich allmählich die Berge erheben. 1 Seine Sprache exhält expressionistisches Gepräge. Mit Absicht hat der Dichter die expressionistischen Stilformen gewählt. Die Worte sind Pfeile, sie müssen das Innere treffen und es beseelen. Er wählt Adjektive, die die Hauptwörter am knappsten ausdrücken. Neue Worte entstehen wie; zerquetschter Schlaf, heisses Haar, rote Blicke und viele andere. Er w staunliches leistet Unruh in Wortzusammensetzungen. Fir kommt auf diese Weise zu eigenartigen Wortneubildungen. So spricht er von: Feuerbad, Fieberfrost, Himmelssäule und Zungenlust. Das emotionelle Wort ersetzt einen komplizierten Satz. Hierüber aber sagt Fechter: "An diesen sekundären Dingen, scheitert gewohnlich die Diskussion. Der Dichter setzt Gefúhlsbesitz ohne Diskussion voraus. Er stellt das Fühlen allein auf sich, will die Erfullung des Wortes allein der Seele auferlegen, ohne zu fragen, ob selbst ein reicher dichterischer Gefuhlsbesitz diesem Leben vom seelischen Kapital auf die Dauer gewach *

1 Kasimir Edschmidt, Erühe Manifeste: Epochen des Expressionismus (Darmstadt: Hermann Luchterhand Verlag, 1960), S. 38. 
sen ist." ${ }^{1}$ Unruh kennt diese Gefahr, deswegen kehrt er sich bald wieder vom Expressionismus ab. Der dritte Teil der Trilogie enthält fast kein expressionistisches Geprage mehr. Er benützt diese Sprache in den ersten Teilen, um das Gefühlsmässige seiner Idee zu intensivieren. Nur aus Chaos glaubt der Dichter ein neues Werden schaffen zu können.

Die Gestalten dieses Chaos sind Urmenschen, Notwendigerweise drängt sich dem Dichter als Problem der künstlerischen Jǘsung die Frage auf, welches Gesicht diese Menschen haben müssen, um Geschöpfe des Chaos zu sein. Unruh fand die Lösung im Pathos: die Gestalten sind pathetische Geschöpfe. "Ein pathetischer Mensch", sagt Emil Staigex, "ist bewegt von dem, was sein soll: und seine Bewegung ist gerichtet wider das Bestehende." 2 Darum geht es Unruh, hier das Bestehende zu vernichten. Der Dichter wollte Leidenschaft, Sturz und Aufschwung zum Absoluten, taumeinde Erschütterungen, Vision und Prophetie. Sie sind die Erscheinungen eines Umsturzes und bedeuten "den Beginn des Kampfes gegen die Zeit und ihre Realität. Man begann, ... im Ansturm des Geistes den Feind zu umarmen und zu vernichten. 13

1 Paul Fechter, Das Europäische Drama, II (Stuttgart: Metzler Verlag, 1930), S. 418

2 Emil Staiger, Grundbegriffe der Poetik, 4. Aufl. (Zürich: Atlantis Verlag, 19597, S. 151.

3 Kurt Pinthus, Menschheitsdämmerung: Ein Dokument des Expres sionimus (Hamburg: Rowohlt Verlag, 1959 ) S.X. 
Die Muttergestalt wird zurn Träger des Menschlichen, wenn sie das Schicksal in sich aufnimmt. Sie begegnet dem Nicht-Menschlichen, dem Staat, der sie zurn Angriff herausfordert. Zwar findet sie, wie die Soldaten in "Vor der Entscheidung", den. Tod. Sie, die die Quelle und das Symbol der Welt ist. Sie überwindet sich selbst und opfert sich. Ihr Tod aber ist der. Anfang eines neuen Werdens.

Unruh's Tragödie "Ein Geschlecht" ist der gewaltige Ausbruch einer bis in ihre Tiefen erschütterten Seele. Aber dieser Seelenstrom mündet nicht in die unendliche Vielfalt der Weltendinge, er rauscht dem einen grossen Ziel zu: eine neue Welt. In diesem Stück stellte er den Umsturz der alten Welt dar und zur gleichen Zeit das Erwachen einer neuen Welt. Was wäre aber der Sinn des Erwachens, wenn es sich nicht in Gestaltung auswirkte! Hierzu aber bedarf die Welt der männlichen Tat. Das Weib ist der Ursprung, der Mann erst schafft aus dem Ursprung die Vollendung, Dietrich, der jungste Sohn, ver. sucht diese Vollerdung in "Platz" zu schaffen. Und zwar durch die Idee einer ewig neuen Liebeseinheit.

B. Die Ordrung in "Platz".

Auf die titanische Tragódie folgt als zweiter Teil der Trilogie das Stuck "Platz", vorn Dichter ein Spiel genannt. 1 Beide wurzeln immer

1. Fritz von Unruh, Platz (Müunchen: Kurt Wolff Verlag, 1.920). 
noch unmittelbar in den Ereignissen und Stümen der Kriegs- und Nachkriegszeit. Sie versuchen das Verneinende des ersten Weltkriegsgedichtes zu überwinden, das Bejahende festex to packen. Der Ruf des Dichters zum Umsturz hat sich im "Geschlecht" zum Chaos verwandelt. Im "Platz" findet das Chaos Raum und man spürt eine gewisse Ordnung, die die neue Welt (im dritten Teil der Trilogie) einleiten soll. Dietrich, der jüngste Sohn, aus dem "Geschlecht", wird von den jungen Soldaten geschultert auf den Platz getragen. Geschwellt ron den Mutterworten, glühend vor Wut, will er die Machthaber, die Anstifter des Mordes treffen und fallen. Mit der Lust zur Revolution stürzt er die Ratsherren, die Kommandanten wie Spielzeug um. Der Oberherr wird schattenhaft, ja wird sogar eine lebende Mumie im Sarg. Sein Leben ist zu Ende, auch wenn er noch zu atmen meint. Der Schópferhauch, das "H!", das der Oberherr durch Pflicht- und Waffengebot er=sticken wollte, ist längst in ihm erstorben. Graf Gutundblut verfällt dem Blödsinn, seinen Leib beschäftigt nur noch die Wohllust der Hofjungfrau Bianka. Der Greis, der Senior des Staates, ist der irrsinnige Kommandant des Platzes. Auch er ist ein rücksichtsloser Verteidiger der alten Macht. Er sieht die Verwirring, die Dietrich anrichtet, die die alte Macht zu vernichten droht. Christlieb Schleich ist einer, der immer die Seite der Sieger wählt. Aus allen Situationen versucht er, Vorteile zu erlangen. Er ist derjenige, der am Ende als Triumphator aus dem Karnpfe kommt. 
So stehen die beiden Extreme einander gegenüber. Die Machthaber als Vertreter der alten Welt und Dietrich als Vertreter dex neuen. Er ist ganz auf sich allein gestelit. Nur Irene, eine Tochter des Ober herrn, bleibt ihm treu. Sie zweifelt auch dann nicht, als er sich selbst zu verlieren dr ht.

In diese Welt des Platzes stürmt Dietrich mit dem Willen zu einer fewaltigen Revolution. Er kommt mit der Überzeugung, dass auf "die Kasernen der Gewalt" eine zerstörende Lawine herabrollen müsse. Er fihlt in sich die Kraft, aus der abbruchreifen Welt eine bessere Welt. atufwachsen zu lassen. Ein Gedanke erfullt ihn aber bald und lässt ihn nicht mehr los: eine Revolutiori kann das entsetzliche Machtproblem nicht lösen. Die Revolution wechselt zwar die Machthaber aus, aber nicht die politische Struktur. Eine andere Waffe muss gefunden werden! Aber bevor Dietrich diese Waffe findet, macht er eine tiefgreifende Wandlung durch und zwar die Wandlung seiner' eigenen Seele. Es ist die grosse Frage an die eigene Personlichkeit: Bist du Herr deiner selbst, hast du in dir schon der Welt des multterlichen Geistes Gestalt gegeben ? Kannst du die Welt verwandeln, solange du dich selbst nicht verwandelt hast?

Bald spürt er, dass an eine Erlösung der Welt nicht gedacht werden darf, ehe nicht der Einzelne zuvor sich selbst im Eros der Mutter geläutert hat. Und diese Reinigung erschaut Dietrich in der Formung seiner Liebe zu Irene. Doch seine Läuterung allein genügt nicht. Mann 
und Frau müs en erkennen, dass in ihrem Leben jede gegenseitige Machtgier, jede instinkthafte Triebleidenschaft gebändigt werden. müs -. se, damit aus dieser Liebe die Einheit werde. So wird Dietrich statt Revolutionàr der Gesellschaft Revolutionär der eigenen Seele. Oder wie Sokel es ausdrückt: "Das Erlebnis, das Dietrich die 'wahre Re.volution' offenbart, ist die Liebe." 1 Das Sinnbild der heiligen Glut der Liebe finaet Dietrich in einer Feuerlilie:

O Feuerlilie, Rest von Sonnenstrahlen, der Bienenwelt als Leuchtturm hingestellt a fuch meine Seele da es dunkel wird. OFeuerlilie, brennendes Gefáss ! : : . fuhrst du mich durch das Dunkel ! Liebesstern hell glänzend aus dem Labyrinth der Schatten zurin neuen Herzen ? Irgendwann, ich fühl's mutss sich vor deinem. Hauch dies Purpurschloss mir "offnen, wie ein Märchen vor der Fee. 2

In seinem Kampf mit dem inneren Feind, seiner eigenen Seele, verliert er den Weg aus dem Labyrinth der Schatten, aber das Licht der Blume fuhrt ihn zu Irene:

Mich glüht ja Liebe in einzig Eins ! Aus Liebe nur werd' ich mein Ich erlósen... Eh ich die Glut, die süsse Geistesflamme im Blut empfange, aus dem Blute lose, das schon in flutender Bewegung mächtig mich auf zur Schopfung reisst -, ehe ich das tue, ${ }^{3}$

1 Walter H. Sokel, Der literarische Expressionismus (München: Albert Iangen und Georg Midler Verlag, 1959), S. 241

2 Unruh, Platz, S. $38,39$.

3 Ibid. , S. 41 
Hier ber"uhrt Unruh das, worum es ihm geht; um eine Erlösung des

Blutes im Geist und die Erlósung des Gieistes im Blut, um eine Einheit wer Lebenselemente im liebenden Menschen. Auf diese Lebensbegegm nung zwischen Dietrich und Irene hat bereits Walzel hingewiesen und erwähnt, dass noch kein Dichter diese Gedanken auf die Bühne gebracht What: "Da regt sich mehr als der alte Gedanke einer Emanzipation der * Frau. Allein dort, wo zuerst fur das Weib das Geistige des Mannes in Anspruch genommen wurde, in der deutschen Fr"ühromantik, gibt es 13 Vorklänge von Unruhs Weckruf, Friedrich Schlegels "Lucinde" geisselt thenau das, was fur Unruh Anlass zu Klage und Anklage ist. "Da liebt... * der Mann in der Frau nur die Gattung, die Frau im Mann nur den Grad. * seiner natürlichen Qualitäten und seiner bürgerlichen Existenz." I

Unruh geht weit über diese Feststellung hinaus, weil er ihm um den "Bund des Geistes mit dem klopfenden Herzen" geht. Durch das Weib kommen die zwei Lebenselemente im Mann zur Einheit:

Ein Mann, ein Weib, ein Kind, darüber hell als ihrer Seelen Melodie ein Kreis ? Ein neuer Adam, herrlich, der die Eva zart eingefügt als Fleisches Uberwindung den Einklang seines Gieistes wiedergab ? ... Das Paradies erobert und der Mensch der Schöpfung Gott! Der Schöpfung seine Liebe ! 2

Nur von der Frau kann die Erneuerung ausgehen. Das meint im "Ge--

1 Oskar Walze1, "Fritz von Unruh", Germanisch-Romanische Monatsschrift (Heidelberg, 1921), S. 267.

2 Unruh, Platz, S. 48. 
schlecht" schon die Mutter, wenn sie am Ende ruft: "O Mutterleib... dú sollst das Herz im Bau des Weltalls werden." 1

Aber der Weg zu dieser Frau ist lang. Im Kampfe um diese Liebeseinheit erkennt Dietrich seine Sendung. Und wenn er glaubt, die Frau gefunden zu haben, da verschwebt das Bild der mütter.ichen Irene in die fleischlustige Dirne Hyazinthe, Irenes Schwester. Zweifel an seiner Sendung steigen in ihm auf. Die Feuerlilie, die er Irene als Sinnbild der Liebe und Reinheit ins Haar gesteckt hat, die aber von Hyazinthe vernichtet worden ist, leuchtet ihm nicht mehr. Die Lilie Huss erst in seinem Herzen selbst Wurzel schlagen. Noch ist das Triebhafte, das Tier in ihm nicht erstorben. Sein Geistwille ist ge schwächt. In dieser Verwirrung siegen die Vertreter der alten Macht. Der Oberherr und der Greis fassen wieder Mut. Sie sehen jetzt in Dietrich den jungen, nur anfangs gefährlichen Stürmer, dessen begeistertes Ideal an den Klippen der Utopie zerschellen müsse. So trium phieren die Machthaber über den Jungling. Sie sind Vernichter der Kraft Dietrichs, in dem Sinne, dass sie für Dietrich nichts anders sind als Mächte seiner eigenen Seele, die es zu überwinden gilt. Er erkennt, dass es sinnlos wäre, den Oberherrn zu ermorden, bevor er ihn nicht in sich selbst getötet hätte:

Lebt ich nicht selber festgekettet ? Sklave jedweder Gier ? ...

1 Unruh, Ein Geschlecht, S. 65 
Wurd ich nicht meiner Seele Seelenratte und meines Herzens eigener Oberher $r$ ? Dich töten? Mich!. Solang ein Oberherr a us mir sich neue Köpfe bilden könnte ... Drum würg ich dich in mir. 1

Aber anfangs gelingt es Dietrich nicht, die Mächte zu thberwinden. In einer Szene verkündigt der Oberherr die uralt skeptische Erkenntnis vom Gang der Welt:

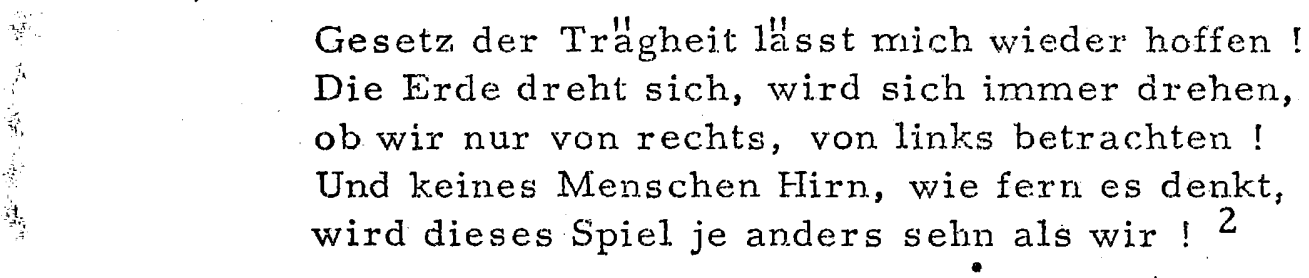

Aber Dietrich sieht die Erde anders. Er ist jetzt noch gesetzlos, da er in sich die alte Masse zerbrochen hat und noch nicht ein neues Gesetz... in sich verwirklicht hat. Solche Freiheit vom Gesetz ist schwerer zu ertragen als der Druck des Gesetzes. Dietrich ist sich dieser schmerzlichen Lage jedes ringenden Menschen in Zeiten neuen Werdens bewusst. Voll Sehnsucht betrachtet er den Globus, in dem er seinen Pol findet:

Könnt ich in mir, wie du, geliebte Kugel, Gesetz des Tanzens ohne Grübeln tragen. Vom Mittelpurkt nach allen Seiten wachsend, bis sich die W"llbung baut und jeder Atem den Geist berührt, in dessen Hauch wir fliegen !... Wo ruht in mir der Pol ? Heisst er Irene ? 3

1 Unruh, Platz, D. 43

2. Ibid., S. 57

3 Ibid., S. 84. 
Jetzt erreicht das Stück seinen Hóhepunkt: das Spiel mit dem Globus, dem beide Liebenden, Dietrich und Irene, sich entgegen rollen. Das Schicksal der Welt rollt $\mathrm{ab}$ in der Spannung zwischen Mann und Weib. So hat auch das Gesetz des Lebens seinen Pol weder im Manne noch im Weibe, sondern in beiden zugleich. Hier problematisiert sich das Erlebnis nicht mehr als Zufálliges von einem Mann hin zu vielen Frauen, Wie in Brechts "Baal", oder Schickeles "Hans im Schnakenloch", sonern als einmaliges, ganz allein zwischen dem einen Mann und der einen Frau. Ein Erlebnis, das nur aus Liebe entstanden ist. ${ }^{1}$ Aus dieser Liebeseinheit soll die Ordnung, der neue Kosmos entstehen. Die schöpferische Liebe ist fur Fritz von Unruh lebendig im Wesen dex Frau, von ihr aus erneuert sich die geistige Formkraft des Mannes. In Irene sieht der Dichter eine solche Frau. Aus ihren Worten spricht die kosmische Liebe:

Lass uns wie Blumen, Sterne, Mücken, Wolken im Schöpfer sein! Nicht zweifelnd, Herz geschieden. Sind wir im Schöpfer, sind wir in der Liebe! Sind eins! Sind Mensch, sind Gott und Welt, Sind Freude ! ${ }^{2}$

Jetzt hat Unrub endlich gewonnen, was als neue hohere Pflicht der alten Pflicht Stich halten kann. Von dem schwererkämpften Standpunkt sieht er zurück auf die Ahnungen seiner ersten Werke, Als Motto vor S. 334

1 Max Picard, "Expressionismus", Die Erhebung, I (Berlin; 1919). 2 Unruh, Platz, S. 84. 
Prinz Louis Ferdinand hatte gestanden: "Wie über Sterne das Gesetz, erhebt sich "uber Menschen die Pflicht gross und ernst". 1 Hier kampften der Prinz und Iuise gegen das "du sollst". Sie versuchten die neue durchgeistigte Ehe zu schaffen.. Luise aber klammerte sich an die alten Vorstellungen von Sittlichkeit und lährnte dabei den. Wagemut des Prinzen. In "Vor der Entscheidung" erklang die Frage nach den neuen Recht der Pflicht. Da sagte der Ulan:

Wilì's Pflicht, zu sehen Und dennoch mitzufechten ? Ist's Pflicht zu gehen aus diesen Wurgenachten ?

In seiner Kriegsdichtung "Opfergang" sagte einer:

Pflicht! Wahrlich der Name ist gross und schlägt jede eigene Regung um. Klein !... Dass wir schnauzen, wie ein General, und unsere Seele abtóten, das nennt sich heute Pflicht! Dex Krebs am Herzen des Volkes ist sie ! Sie trägt eine Pickelhaube, nicht: unsere Liebe ! 3

Das Gesetz des "du sollst" schlug gegen den Menschentrieb "ich will". In der Trilogie wird das Gebot "du sollst" aufgehoben durch die. "Liebe und Freude", in welchern Gefuhl die Welt ihr Gleichgewicht finden wird.

1 Unruh, Dramen, S. 134.

2 Unruh, Vor der Entscheidung, s. 19.

3 Fritz von Unruh, Opfergang (Berlin: Erich Reiss Verlag, 1919), S. 86 
Jetzt glaubt Dietrich die Waffe; die Liebe, gefunden zu haben, womit er die Machthaber vernichten und eine neue Welt gestalten kann. Irene verlässt um Dietrichs Willen ihren Vater, den Oberherrn. Hiermit bestätigt sie seine Niederlage. Er wird Mumie im Sarg. Er hat. das. "H", den gottlichen Atem, den Hauch des Lebens gelóscht, statt es in lebendigen Odem aufuulösen. Der Schöpferhauch, den er durch Pflichtgebot ersticken wollte, ist längst in ihm erstorben. Das " $H$ ", das aus dem Mund der Mutter die Welt neu begeistern soll, ist die Zelle: die Trägerin der Liebe. F"ur Dietrich ist der Oberherr so gut wie tot. Der Greis, Senior des Senates, wird der Vertreter des Oberherrn. Es gelingt dem Greis, Dietrich zu überreden den Aufruhr offiziell abzulenkerı. Dietrich schliesst Kompromisse; ein Dokument wird unterzeichnet. Hiermit wird Dietrich zur gleichen Zeit Verräter seiner Brüder und seiner Mannschaft. "Verraten um ein Mädchen! Es ist wahr !"l sagen seine Anhänger, die seine innere Wandlung nicht verstehen können. Der Greis triumphjert. Dietrichs Schicksal liegt jetzt in der Hand des Senators, der sagt:

Er bleibt leben! Sterben ist nicht viel -
die Rache fordert mehr, als einen Seufzer !
er soll das Blutbad seiner Bruder sehen !

Es ist ein grausames Wüten der Liebesgeister, in das der Dichter Dietrich und Irene hineinstellt. Der Tanz der Sinnlichkeit in den

1 Unruh, Platz, 5.78

2 Ibid., S. 104 
gemeinsten Variationen rast um ihre Gestalten. Die Entscheidung in diesem Ringen fallt durch die liebesglut Irenes. Thr starkes Glauben an seine Sendung ist stärker als die Mächte, die ihre Einheit zerstören wollen. Sje ist und bleibt dex Unterstützer von Dietrichs Kraft. Auch werin er irre wird an seinem Wege, wenn der männliche Führergeist wieder in ihm erwacht. Er glaubt, um Irenes willen, seine Aufgabe den Massen gegenüber doch verraten zu haben. Denn immer wieder bezweifelt er, dâss schon eine neue Welt geschaffen werden könnte. Nun aber futhlt sich die alte Macht wieder ganz als Herrin der Lage. Dietrich schreckt zu dem Bewusstsein auf, dass er doch Verräter des Volkes geworden sei und glaubt, dass Irene und seine Jiebe zu ihr ihn seiner Pflicht entzogen habe. Mit Hohn lóst er sich von der zärtlich und rein Liebenden los. Er lässt Ir ene deshalb nur als Wesers seiner männlichen Lust gelten, um desto unbeschwerter "uber sie hinwegschreiten zu können: "Behalte unseren Tag als heitres Spiel und sei, dass du's genosst, zufrieden." 1 Die Worte schneiden ihr ins Herz. Und wenn er wieder eine Revolution der Massen vorbereiten will, sagt sie:

Mord! Krieg und Pest! Das kannst du! Also fuhre! Doch wenn du bebend einst vor Menschen tretend, ... der Tat nur Plunder umhängst, dann schaudre vor jedes Zufall schweflicher Erscheinung; denn du wollst Schópfer sein, eh du selbst Schöpfung wurdest. 2

1 Ibid., S. 131

2 Ibid. , S. 138 . 
Aber sein Zweifel, ob sein Kampf um die Liebeseinheit dieWelt und die Menschen erlösen kann, ist stärker als zuvor: "Ha ! W"uchsen wir, wir beide auch in eins-, erlóst's die Brüder, wenn wir uns erf'ullen !" 1 Irene antwortetihm mit der tiefen Weisheit ihres Herzens:

Wie anders hoffst du Menschen zu erlösen! In ihre Tränenkammern Tanz zu bringen! Das Trunkene von Blick zu Blick zu halten -, wern sich zwei Menschen von der Welt gelost in stillen Schaudern in ihr Herz erheben.

Mit einer erschütternden Inbrunst $r$ ingt das Weib um die Seele des Mannessund um ihre Befreiung von dem Machtdruck, damit sie aus der Gewaltherrschaft zur Gemeinschaft der Liebe fábig wurde:

Sterben war der Toten Tat.
Alle Guten, alle Bösen
aufzul'ósen
sei der Liebe Jubelwerk ! ${ }^{3}$

Wieder zeigt sie ihm den richtigen Weg. Irenes Glut und Sicherheit vollzieht in Dietrich die letzte notwendige Wandlung des männlichen Geistes aus dem mütterlichen Geiste der Liebe. In tief innerem Erleben erkennt er, dass die Liebeseinheit der wahre "Weltenherr" sei, dem man sich zu beugen habe, um eine neue Welt zu gestalten:

Das wir in der Jungfrau Stern unsern wahren. Weltenherrn: I.iebeseinheit, dich erkennen dazu, Mutter, sage: Amen! 4

1 Ibid., S. 142

2 Ibid.
3 Ibid., S. I 48

4 Ibid., S. 149 
So hat sich in Diet rich und Irene das Erbe des mütterlichen Geistes erf"l11t. Die Míglichkeit, eine neue Welt zu gestalten, ist da: "Heut" ist der Jungste Tag ! Und gestern war der Tod !" 1 Ein neues Geschlecht wird das alte zerfallende ablösen.

Sie reichen sich die Hände:

Der Geist spricht: Komm,

Die Braut spricht: Komm ! 2

Aus der eigenen Seele erkennen sie ihre tiefere W"uxde. Die "neue Liebe" hat Wurzel geschlagen. Sie entspricht der Synthese von Geist und Herz, für die Unruh in seinen Reden nach dem ersten Weltkrieg als der einzigen Hoffnung fur eine neue Welt wirbt ! 3

Dietrich und Irene sind die Träger der neuen Welt, denn die vollkommene und erfulllte Liebe zwischen Mann und Frau sichert den Nachkommen eine glückliche Kindheit und bildet damit eine Hoffnung für eine bessere Zukunft. Wie in Tollers "Masse Mensch" wird die Hoffnung von der Gegenwart in die Zukunft verlegt. Doch während sich Tollers Heldin in ihrer einsamen Gefangenschaft, vom Ehemann verlassen, nur an einen abstrakten, religiösen Glauben klammern kann, leben Dietrich und Irene fur die Zukunft. Ihre Hoffnung a uf eine neue Welt ist wirklicher als die von Tollers Helden. Sichtbare Freude und

1 Ibid.

2 Ibid.

3 Unruh, Reden...., S. $46-49$. 
sichtbares Glück zweier Menschen sind ein stärkeres Argurnent als abstrakte Ideen in einem Vakuum. Dadurch, dass Dietrichs und Irenes "neue Liebe"l allen Männern und Frauen ein Beispiel gibt, wird sie eine neue Welt und einen neuen Menschen schaffen.

Die erilosende Erkenntnis der beiden Liebenden wird durchbrochen von der Mannschaft, die Dietrich für Verräter hält. Unter der Führung Schleichs érden beide auseinandergerissen; Dietrich als Verrater der. Rache, Irene der rohen Lust des Volkes preisgegeben. Doch kein. Ge-fuhl der Verizweiflung erwacht in den Helden: "Leben, dennoch Leben !.. Liebestod verführt uns nicht !... Leben, Liebe leben ! ${ }^{1}$ Der Wille zum Leben, auch in seiner schlimmsten Form wird in den Jiebenden lebendig. Sie wissen, sie sind erste 'Träger einer neven Welt und eines neuen Lebens, deren Sinn darin besteht; Kämpfer und Zeugen dafür zu sein, das Erbe des Mutterherzens zu verwirklichen, und durch das Beispiel ihrer Liebe zu zeigen, auf welche Weise allein die Schaffung einer neuen Welt móglich sei: So spricht Irene:

Will's verdienen, will's erwerben, mich aus Muttergnaden wandeln.

Ihrer Erde Feuer erben -, ihre Worte handeln, handeln, bis sich, ... letzte Menschen in ihr Herz gerungen ! ${ }^{2}$,

Und Dietrich, innerlich von allen Schlacken befreit, ist von seiner Sen-

1 Unruh, Platz, S. 155

2 Ibid., S. 156 
dung von neuern durchdrungen:

Unsre Iuilie blühet wieder,

fühl ihr exstes Blumenblatt -

wachsen, wachsen aus uns beiden.

Blüh empor zum Wandelstab der Welt ! 1

Nach dieseh Worten schlägt die aufgewühlte Masse über die beiden zusammen und reisst sie mit hinweg. Aber ihr Liebesdunst hat in einigen der Soldaten Wurzel geschlagen. Jubelnd schreit ein Soldat:

Viel eher würdet ihr mit euren Häriden

ti dem Sonnenaufgang wehren, als dem Feuer, von dessen Glanz ich nur ein Flärnmchen bin. 2

Auch die Toêhter, die am Leben verzweifelnde Schwester Dietrichs, sagt am Ende des Spiels:

Wird mir dein Aug Glanz? Auch mir ?

Ich sehe tief in das Herz der Welt da deine Kraft aus neuer Liebe neue Menschen schafft. 3

Das Spiel "Platz" wurde 1917 begonnen und 1920 beendet. Es ist ein Drama der europäischen Revolutionszeit und' zwar in doppeltem Sinne: hier spiegelt sich die ganze Erbärmlichkeit der europäischen Wirklichkeit, wie sie sich damals dartat und auswirkte. Hier spricht aber auch der andere und tiefere Sinn des Kriegsgeschehens, der Anbruch einer Wandlung des Menschen.

1 Ibid.

2 Ibid., S. 159

3 Ibid. 
"Platz" ist ein Abbild der Kriegs - und Inflationszeit. Menschen, die ihre Gesichter verloren haben, Zweifler, die aufs Alte schwören. Machthaber, die sich vor den Wundern ihrer Geilheit selber überschlagen. All dies ist mit Kraft und Erkenntnis dargestellt. Und mitten hindurch schweift Dietrich, der um die Verwirklichung seiner Weltidee durch die Liebeseinheit kämpft. "Europa wird der Kulturwelt noch einmal ejn durchaus neues autonomes Ethos der Lebensgläubigkeit. bieten müssen - oder es wird als lebendige schöpferische Geistesmacht aus der Entwicklung der Menschheit verschwinden. Vorläufig arbeitet es noch an seiner inneren Selbstzerstörung.... dass ja eine Vorbedingung der inneren Wiedergeburt, das grosse Stirb und Werde, ist." 1 Nicht umsonst ist dieses Stück vom Dichter ein Spiel genannt worden. Es bedeutet und ist der Übergang vom Chaos des "Geschlecht" zu der Mythologie eines neuen Kosmos. Die Liebeseinheit ist es, die die Ordnung im "Platz" bewirkt.

Auch in der Sprache spürt man eine gewisse Ordnung. Wenn im "Geschlecht" das Pathos von Sprecher zu Sprecher entbrannte, so vermisst man hier die grosse Stimmenfuhrung. Nur einige Pathetiker er . scheinen in diesem Stück. Schleich's Sprache, zum Beispiel, ist grotesk. Sie ist das Gegenteil, ja Widerspiel der Sprache Dietrichs. Sie ist überscharf und ganz unlyrisch:

1 Hans Mühlestein, "Europäische Kulturgegensätze", Handbuch der Politik, V (Berlin, 1922), $171-172$. 
Maul zu ! Erlebnis totnackt, lichtgereckt. Ins Loch zurück! Walküre? Willkür jetzt. Gesetz? Zersetz. Mir nur, Erstanfang! Leiter hoch zum Ich! Schleich, du !

Dietrichs Verssprache dagegen ist oft lyrisch. Am Ende findet er die Sprache, die fähig ist, das Ethos der Liebeseinheit auszudrücken:

In ungemessen Horizont verloren schau ich ein Land, da alles Wohnung findet. Wo Blumen wippen, Sternchen, sonnenbunt.

(Z) Zwar herrscht das Ekstatische, das der Expressionismus für sich beansprucht, noch vor. Es ist diese ekstatische Breite in Unruhs Sprache, die viele Kritiker zum Vorwurf seiner Gedanken machte. So schreibt Albert Soergel über die ersten Teile der Trilogie: "Der Versuch, den neven Menschen und die neue Welt in symbolischer thberholung darzustellen, ist an Unruhs Sprache gescheitert. Sie ist ekstatisch, pathetisch, aufgeregt. Die Gestalten schreien und gestikulieren, aber man glaubt nicht an die visionären Erlebnisse, von denen sie stammeln. ${ }^{3}$

Aber Unruh schrieb für die Bühne, er will keine Rhetoriker sondern Schauspieler. Er bedarf der lebendigen Vertreter seiner Worte, die sich mit ganzer Leiblichkeit dem Spiel widmen. Jeder Schauspieler muss aus seiner privaten Persönlichkeit hinaustreten, wenn er eine

1 Unruh, Platz, S. 60

2 Ibid., S. 152

3 Albert Soergel und Curt Hohoff, Dichtung und Dichter der Zeit: Vom Naturalismus bis zur Gegenwart, II (Dusseldorf: August Bagel. Verlag, 1963), 252. 
dichterische Gestalt verköpern soll. Er muss sich in sie verwande 1 . Diese Wandlung kann aber nur durch Ekstase bewirkt werden. ${ }^{1}$ Wie können die Gestalten dann nicht an die Erlebnisse glauben, von denen sie stammeln? Unruh ist von tiefem Gef'thl durchdrungen, was sich in der Dichtung sehr bemerkbar macht: sie zeigt eine starke innere Bewegung. Dieses Ringen mit sich selbst beobachtet man in der DarsteIhung der Personen. Dex Ausbruch eines heftigen Gefuhls, begleitet von starken Willensantrieben, spiegelt sich in der Sprache wieder. Eine Entwicklung ist spürbar, die wie eine schnurgerade Linie durch die Trilogie geht, die auf eine neue Welt hinweist. Die Spannungen der: HAndlungen werden durch die elkstatische Sprache auf die Spitze getrieben. Und mit Absicht hat Unruh sie so dargestellt, damit die Gestaltén im Chaos das Sichselbstzerbrechen zeigen konnen, das ja eine Vor-. bedingung der inneren Wiedergeburt ist.

Gleichwohl macht sich hinter diesem Chaos eine strenge, künstlerische Hand fuhlbar. Unruh will mehr als ubersteigerte, ins Grenzenlose hinausstrebende Bewegung. Denn selbstverständlich wird die Steigerung ins Chaotische nicht anhalten, sondern Raum geber. Dass die Sprache sich richt in Masslosigkeit entfaltet, zeigt Binding bereits, wenn er sagt: "Wenn es keineswegs als kuhne Behauptung bezeichnet wurde, dass in Unruh sich das grosse Drama gebären werde, so wird

1 Felix Fmrnel, Das Ekstatische Theater (Prien am Chiemsee: Kampfmann und Schnabel Verlag, 1924), S. 25. 
diese Hoffnung durch die geradezu spielende Übersteigerungsmöglich keit genährt, die sich von Stük zu Stück erweist. Reissend nehmen die Dimensionen zu, Spannungen werden mehr und mehr ins Unabsehbare hinausgefuhrt und dann doch sicher an einem jenseitigen Ufer auf gesetzt und verankert." ${ }^{1}$ Die Entwicklung von Uni uhs Idee ist nicht an dej Sprache gescheitert. Im Gegenteil, die Sprache hat sie nur intensiviert.

Wohl aber ist der. Dichter seiner Fischütterung noch nicht Herr;

ther will ihrer noch nicht Herr sein. Er will, dass diese Erschütter ung weiterzeuge in ihrer Wirkung auf die Menschen. Er will, dass der

Aufprall seiner neuen Liebe Menschen mit in seine Tiefen und H"hen reisse, damit aus solcher Überwältigung die innere Wandlung erstehe. Vielleicht hat er deswegen den dritten Teil der Trilogie erst im Jahre 1958 beendet. 2 "Es ist ein Zeichen seiner schoopferischen Weisheit, dass ex seine Trilogie noch nicht beendete", 3 sagt Korodi. Denn "Dietrich" zielt auf die Kronung seines Gesamtwerkes hin. Die Verantwortung Unruhs ist in diesern. Falle so gewaltig, dass hier die ZahI der Jahre überhaupt keine Rolle spielt.

1 Rudolf Binding, Rufe und Reden (Berlin: Erich Reiss Verlag, 1924), S. 43 .

2 Unterhaltung mit Kurt von Unruh, München, Märr, 1967.

3 Eduard Korodi, "Fritz von Unruh", Dex Lesezirkel, 7. Heft, V (Zürich, 1917), 104. 
C. Der neue Kosmos in "Dietrich."

In den zwei ersten Teilen der Trilogie hat der Dichter die neue Welt noch nicht erreicht. Bis jetzt stand sie under dem Gesetz der Wandlung. Bis zu dem Ende dieser Wandlung führte uns Unruh im "Platz": Dietrich und Ir ene fanden die Liebeseinheit, die die erlo"sende und gestaltende Macht ist. Aber in die verwandelte Welt selbst lässt uns der Dichter noch nicht blicken. Wie diese Menschenwandlung sich auswirkt in der alltáglichen Erfulllung des Lebens mit seinen mannigfaltigen und gegensätzlichen Beziehungen, zeigt Unruh uns in "Dietrich".

Dieses Drama zerfällt in ein Vorspiel und drei Teile, die alle vier denselben Umfang haben. Voran geht ein Prolog, der gleich dem Vor - " spiel in New York spielt und Dietrich und Irene vor ihrer Rückkehr in ihre deutsche Heimat zeigt. Dietrich hat in New York ein Hilferuf aus seinem rheinischen Wohnort erreicht. Der Bürgermeister des Ortes hat eine Brücke gebaut, die Symbol des Friedens werden soll. Auch soll die Brücke die Menschen genau so vereinen, wie sie die getrennten Ufer verbindet. Aber die alten Machthaber verlangen den Einbau von Sprengkapseln, weil sie bereits den nächsten Krieg einplanen. Der Bürgermeister kämpft dagegen, da er einen Eid abgelegt hat, nur noch für den Frieden zu kärnpfen. Da er sich weigert, die Forderung zu er fulllen, wird ex erschossen. An seiner Stelle kämpft Dietrich flur die

1 Fritz von Unruh, "Dietrich", Manuskript, 1958. 
Sache des Friedens. Durch seine Liebe-Predigt beweist er den Machthabern, dass Wille zur Macht Deutschland erneut ins Verderben führen wird. Auch Christlieb Schleich, der immer wieder probiert, Dietrich iñ Versuchung zu bringen, scheitert. Nur Irene und die jungen Leute, die das Unrecht des Krieges eingesehen haben, kämpfen auf seiner. Seite. In diesem Kampf opfern sich Dietrich und Irene. Aber ihr Tod ist nicht umsonst, denn viele, selbsi der "feige Sohn" vom "Geschlecht", der so am Leben verzweifelte, erkennen die neue Welt, die Dietrich gestaltet hat.

In "Dietrich" versuchen Dietrich und Irene, die Menschen an ihre neue Idee der Welt zu gewöhnen. Denn so denkt Dietrich: Zukunft bauen will, braucht Menschen. Wie aber: sehen diese Menschen aus? Verdienen sie "uberhaupt den Namen "Mensch"? Die Erfahrung jeder Stunde ruft ihm ein Nein entgegen. Halbmenschen, Halbtiere sind es, versessen a die Machtmittel, die sie beherrscht. Da gibt es den Major und den Greis, deren Motto Wille zur Macht ist. Da ist Schleich, der jede Mode mitmacht und der Dietrichs Geist immer wieder verdunkeln will. Das sind die Hauptsprecher einer Gesellschaft, die dann noch durch viele Nebengestalten vertreten ist. Gestalten, die zum Untergang reif sind, aber zu jeder Neuschopfung noch unfähig. Durch seine Liebe-Predigt, versucht Dietrich, die innere Wandlung im Menschen zu bewirken. Deswegen wird das Thema "Iuiebe" hier noch dringlicher. Denn um eine Wiedergeburt des Menschen nach dem Mas- 
senmord des Krieges möglich zu machen, muss der Einzelne mit sich selbst ins Reine kommen, muss das Verhältnis von Mensch zu Mensch neu begründet werden.

Die Jahre im Exil hatten Dietrichs Haltung nicht geändert. Drin.gender denn je fuhlt er die Notwendigkeit, die Welt neu zu gestalten. Mehr und mehr verlangen die Menschen nach Frieden. Die Themen, die in diesem Drama stark hervortreten, sind Friede und Liebe. Sie sind die Mächte, die die neue Welt gestalten sollen.

Seton die ersten Worte Dietrichs geben das Thema an:

W. Konnt ich dir jetzt die Friedensbotschaft bringen, vom Gift der Waffenträume Dich befreien, die Dich verderberi ... Heimat! ${ }^{1}$.

Aber das einstimmig beschlossene Wehrgesetz sagt, dass jeder, der den Militärgeist schädigt, ein Feind der Menschheit sei und zum Tode verurteilt werde. Unter solchen Umständen predigt Dietrich, der als einer dieser Verbrecher angesehen wird, seine Idee. An der Stel le der jungen Leute, die wieder zum Soldatsein gezwungen sind, kärmpft er für die Friedensbrücke. Die Mannschaft ruft: "Jetzt führe uns ... die Schicksalstunde ruft !" ${ }^{2}$ Statt F"uhrer einer Revolution zu werden, wird ex ein F'uhrer, der den Leuten den Weg zu ihrem Bessern Ich, zum innern Werden zeigt: Dietrich erzählt ihnen, wie er seinem Besseren Ich begegnete:

1 Ibid., S. 32

2 Ibid., S. 33 
Dann zum Polarstern zeigend sprach es in das Konzert der Wellen:

'Bruder, warum verfolgst Du mich ?' 1

Hi er erwähnt der Dichter durch Dietrich sëine eigene inneie Wandlung damals während der Trommelfeuer vor Verdun. Es ist die anrührende Frage, die ein unbekannter Soldat dem Dichter gestellt hat. 2 Es ist jetzt Dietrichs Motto, dass in den Leuten die Wandlung bewirken und ihnen den Weg zu Gott seigen soll:

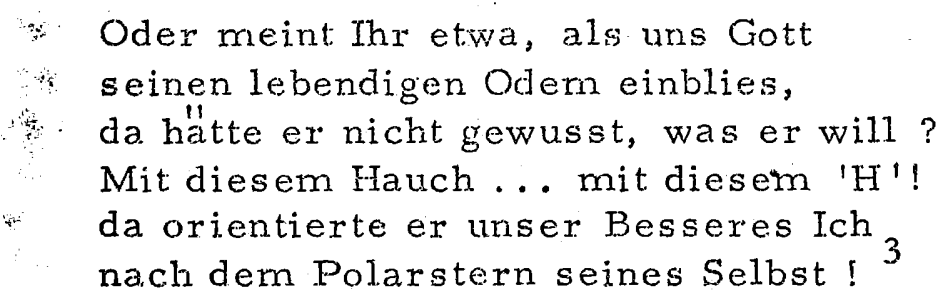

Hier berührt der Dichter seinen tiefen religiosen Glauben, dass Gott dem Menschen seinen lebendigen Odem einblies. Seit dieses Bild in unser Bewusstsein geprägt wurde, sind wir nicht mehr winzig, sondern zum Zentrum des Alls gemacht. Mit diesem Gottes-Anhauch begann unser aller Verpflichtung zum Frieden und zur Brüderlichkeit. Denn Gott ist ein Gott des Lebens und nicht des Todes. Mit diesem Lebenshauch sollen die Menschen das Himmelreich des Friedens in ihrem Innern gestalten. Nur in uns selber kann das Friedenswunder sich erfull.. len. Oder wie Unruh es in eirer seiner Reden als das neue Sittengebot

1 Ibid., S. 35

2 Unruh, Reden..., S. 118.

3 Unruh, Dietrich, S. 36 
sagte:

Du fang an.! Ich fang an ! Wir alle wollen anfangen, die Sündenflut wider das Menschheitgewissen einzudämmern und zu regulieren. Dies allein ist der Weg zur Rettung und zum Frieden ! 1

Durch Dietrichs Predigt vereint, stürmen die Leute zur Brücke, urn den Einbau der Sprengkammern zu verhindern. Irene bittet Dietrich, nicht zur Brücke zu gehen, da sie für sein Leben fürchtet. Er aber sagt: "Besser Tod, als Gott zu schänden, durch dessen Hauch wir leben ..." 2

Wieder kommt Irene ihm zu Hilfe. Sie spielt Theater mit den Soldaten, die Dietrich verhaften wollen, damit er Zeit hat zu fliehen. Sie beschwort die Soldaten mit der Bitte um Selbsterkenntris, mit dem Gedanken an den ewigen Frieden, wenn sie ihnen die Frage stellt:

Was besser ist, das Wehrgesetz und dann vom Krieg vergast, zerschossen, oder zu leben noch - in Blut und Geist zu leben?

Ruft Euer besseres Ich herauf ! Ruft ! Ruft !

Oder habt lhr Angst ?. . vielleicht wird es

Euch dann eine Frage stellen:

'Bruder, warum verfolgst du mich ?' 3

Aber Irenes Beschwörung bleibt ohne Antwort, die Soldaten weichen wie vor einer Irren zurück.

1 Unruh, Reden...., S. 257 .

2 Unruh, Dietrich, S. 37

3 Ibid., S. 44. 
Inmitten dieser Umstände steht Dietrich wieder auf verlorenem Posten. Der Besatzungsmajor will Dietrich beweisen, dass Frieden nur durch Macht bewirkt werden kann: "Și vis pacem ... para bellem!"l Diese Worte hält Dietrich fur eine der grössten Irrefuhrungen und un ermüdlich stellt er denen sein Bekenntnis entgegen: "Si vis pacem parapacem !" Denn dies ist es, was die Dorfgemeinde meint, wenn sie die. Sprengkammern nicht in der Brücke, die sie dem Frieden weihte, dulden will. Der Major wird in die Enge getrieben. Plötzlich sagt er die Worte, die Dietrich tief ins Herz treffen:

Hat Deutschland schon gebüsst, wo büsste es all die Verbrechen an der Menschheit ?... Sthhne ist es fur Schuld. 2

Kiesenhaft ist ihm die Erkenntnis der gemeinsamen Schuld zuteil geworden. Und sagt:

Wer ist schuldlos ?... Ich nicht. Schau ich ins Dunkel meines Selbst,...

So sage ich, wie meine Mutter einst:

'In mir ist jede Schuld !' 3

Mit diesen Worten hat Dietrich das Friedenstor, das Tor zur Vollker . versöhnung weit geöffnet. Hier entspricht ihm die Verkündigung des unbekannten Soldaten in Unruhs Festspiel "Heinrich aus Andernach":

Ibid., S. 52.

2 Ibid. , S. 53.

3 Ibid. 
Keine $r$ weiss, wo die Schuld begann!

Doch der Erste, der des Fluchs unendliche Verstrickung stolz zerreisst und allein nur sich zum Fluch bekennend, wagt zu sagen: 'Ich' der die Schuld der We]t gelóst. I.

Der Kampf wird einer zwischen Nietzsche und Schiller. Mit Nietzsches Worten "Wille zur Macht" versucht der Major Dietrichs Friedenswerben zu vernichten. Unermülich aber verteidigt dieser sich mit Schillers Gedicht "An die Freude". So verschiedenartige Menschen wie der Major und Dietrich auch sein mögen, sie sind doch tief verbunden durch einen einheitlichen. Wandel der Welt. Der Major ist ein Held des Krieges, Dietrich daneben ein Held des Friedens. Der Major ist nur der Held eines schöpferischen, kräftelösenden Krieges: "In dieser Welt, da ist die Macht die hóchste Machtinstanz." 2 Dietrich ist der Held eines schópferischen, kräftelösenden Friedens: "Und das Volk ? von Schillers Geist und Beethovens Musik erregt zur Freiheit ? it 3 Hier liegt die tiefe Einheit: in der Kraft und in der Liebe zum aufsteigenden und schöpferischen Leben. Nur das Heilmittel ist verschieden: Krieg und Frieden. Dietrich beweist dem Major, dass nicht der Wille zur Macht, sondern der Wille zur Freude die L_ösung ist. Entweder, das Volk lässt sich von den himmlischen Feuern, von der Freude, die-

1 Rasche, S. 118

2. Unruh, Dietrich, S. 56.

3 Ibid., S. 61 
sem schöneri Gottesfunker der Lebensverwandlung, endlich zur Begeisterung und zur Liebe eines Friedens mitreissen, oder es taumelt endgültig hinunter in neue Massengräber. Nur die Menschen selbst können sich vor Unheil bewahren. Mit dem Heilandwort an die Menschheit: "Das Himmelreich ist in Dir !" 1 enth"ullt Dietrich die wahre Lo" sung: Diese Gewissheit, dass der schöpferische Gottesfunken in uns selber brennt, ist das Grosste und Wichtigste des ganzen Kosmos. Nur müssêth die Menschen sie erst in sich selbst gestalten. Denn die.ses helle Bewustsein, das wird uns kein Hohn oder keine Macht je verdunkeln können. Nicht die Zustände, sondern die Menschen müssen erst geandert werden, wie Rene Schickele sagt:

Wie ich die Welt will, Muss ich selber erst Und ganz und ohne Schwere werden ! 2

Der Mensch müsse wieder das Herz des Weltalls werden. Sein eigenes Herz, in unlöslicher Verbindung mit dem Geist, müsse der Gott werden, der aus dem Chaos den Kosmos bilde. Zu dem Zweck bedürfe das Herz aber der inneren Freiheit, die in der Absage an alle menschli chen Laster bestehe.

Wenn es Unruhs Absicht war, die neue Welt durch Friede zu gestalten, so ist Friede ohne Liebe nicht denkbar. Denn nur das Ver-

1 Ibid., S. 64

- 2 Pinthus, Menschheitsdämmerung, S. 270. 
hältnis von Mensch zu Mensch kann den Frieden bringen. Das ist Dietrichs "Neue Religion", die er predigt. "Was heisst 'Religio' denn? heisst es nicht Bindung, gebunden an die Einheit alles Seins ?" 1 Solange diese" "Neue Religion", die neue Liebe noch nicht Wirklichkeit ist, kann ein Christlieb Schleich herrschen. Seine Name deutet auf eine symbolische Position imDrama. In ihm hat der Dichter das Kul turschleichertum getroffen, den Kaffeehausliteraten, den Auswurf der seelisch verkrüppelten Schicht, für die das Weib nur Material, die Liebe nurytraselei ist. Krieg und Revolution sind für ihn nur Geschäfte und Mittél, das Ich emporzudrängen. In "Platz" war er der Revolutionär und Politiker. Hier erscheint er als Filmmagnat und verfügt Uuber mehr Publicity und Macht als zuvor:

Ein Filmdirektor aber, das heisst Monarch sein - ohne Paxlament! Heisst Sultan sein plus Harem! Weiberbeauty umdrängt mein Office ! Und das breitste Bett nicht breit genug ist's fír den Nachtbetrieb, Was soll ich in der Politik? no, no ! Wenn ich es will - erscheinen Potentaten in meinen Studios. Feldmar schälle ! 2

Dietrich ist noch nicht immun gegenüber der Gefahr, die Schleich ihm entgegenstellt. Er erkennt in Schleichs Karikatur Züge seines eigenen Wesens, die es zu unterdrücken gilt. Immer wieder versucht Schleich, Dietrich in die Wirklichkeit, wie er sie sieht, zu ziehen:

\footnotetext{
1 Ibid., S. 67

2 Ibid., S. 74,75 .
} 
Dort die Apparate... das ist Wirklichkeit ...

Die Masse lernt nur im Kino auf der

Leinwand die andern Völker kennen.

Die Ku-l-tur sind wir ... Wir zeigen

die Olympiaden wo Bruderlichkeit herrscht !...

Die Liebeseinheit wird jetzt po-po-1är.

Aber nicht internationale Sportkämpfe haben die Menschen bisher der wahren Brüderlichkeit entgegengeführt, die ihnen Freude und Frieden bringt. Nein, alle diese Olympiateilnehmer einer sport]ichen Brüderlichkeit eiltten, als der Krieg sie dann rief, ein jeder zu den Fahnen seines Landes und zum Gemetzel der Unbrüderlichkeit. Denn nicht die. physiche lueistung schafft Brüderlichkeit, sondern allein die seelische Leistung vom Ich zum Du.

Schleich macht die ganze Sache, für die Dietrich kämpft, lächerlich. In seinem Film stellt ex die Dorfgemeinde als Sieger da und nicht die Machthaber. Die Sprengkapseln werden nicht in die Brücke einge mauert. Was in Wirklichkeit nicht durchgesetzt werden konnte, wird im. Film verwirklicht. Schleich, der Kompromisse mit den Machthabern gemacht hat, treibt Dietrich so weit, dass dieser entweder als Komiker im Film mitspielt, oder er wird von dem Kriegsgericht ver urteilt. Er wählt das letzte und zusammen mit Irene werden sie auf dem Friedhof gefesselt:

Hier bleibe ich ! verrate wer

da mag den Frieden, dem die Brücke dort geweiht, - Ich nicht ! 2 
Allein stehen sie jetzt der Masse gegenüber. Dietrich - Irene, das ist der Schicksalsruf, der das weitere Drama beherrscht. Es ist jetzt nicht eir Kampf um ihre eigene Liebe, wie im "Platz", sondern ein Kàmpf, der die Masse überzeugen soll, dass die Liebe in der Einheit des Geistes und Blutes die einzige wahre Friedenskraft ist: "Es gibt keinen andern Aparat des Friedens als den Bund des Geistes mit dem Klopfenden Herzen !" 1

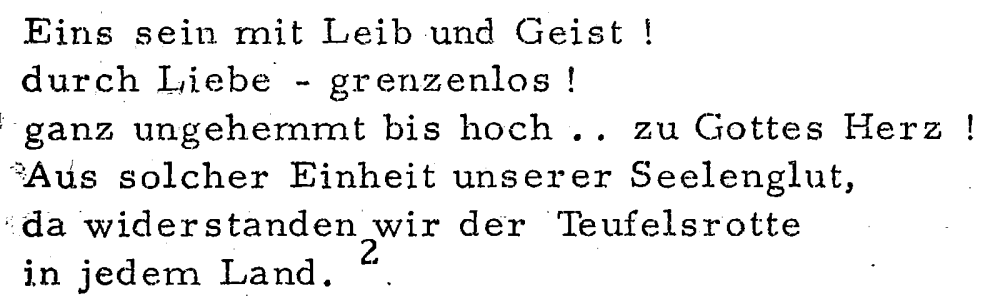

Nach diesen Worten schlägt die aufgewühlte Masse über den beiden zusammen und steinigt sie. Einer trifft Irene. Unruhs ganzes Seelenfeuer, das Ausmass seiner Kraft und Innigkeit gestaltet gerade in dieser Schicksalsstunde den Liebesjubel der beiden, der in Irenes Worten seinen Höhepunkt erreicht: "Du bist mein Licht - und meine Freude ! Du." 3 Als ein unzerstorbarer Fels steht die Liebeseinheit, an der die Welt genesen soll, hier als Vorbild.

Wie verschieden behandelt Paul Kornfeld ein ähnliches Thema in dem Stück "Der ewige 'Traum", in dem die Liebe Carolus und Anna

1 Unruh, Reden ..., S. 16

2 Unruh, Dietrich, S. 79.

3 Ibid., S. 93. 
auch als Vorbild dient. Der Held aber scheitert, er flieht, da er nicht als Vorbild dienen will. Unruh hingegen stellt das Gegenteil dar. In den schlimmsten Situationen siegt die Liebe. Die Liebe Irenes und Dietrichs ist stärker als die Mächte, die ihre Einheit zerstoren wollen. Selbst im Angesicht des Todes siegt die Liebe. Dietrich flieht nicht, wie Carolus.

Aber diese ewig-dauernde Liebeseinheit wird durchbrochen von dem schmierigen Filmmagnaten Schleich, der mit der fast nackten Miss Universe Dietrich in Versuchung bringt:

Boy ! sei nicht blode ! look, noch unberührt vom Männergriff ! look, - wie ein Frühling, look. Trenn Dich von Deiner Frau ! 1

Da Dietrichs Sinne das Weib so stark empfinden, kann er dem Rausch verfallen. "Ihr alle wollt's ?" ${ }^{2}$ fragt er und ist bereit, mit Miss Uni verse zu gehen. Da erscheint Irene. Mit der Feuerlilie flthrt sie ihren Mann wieder a den rechten Weg zur"uck. Sie steht, wie im "Platz", auch hier rein in dieser unreinen Welt. Obschon sie mit Dietrich einige Male in Konflikt kommt, ja, vielleicht gerade deshalb, ist sie die Verkörperurig seines eigenen, nach dem stuebenden und darum von Zweifeln getrubten Innern. Das Innere, das nach Befreiung von dern Machtdruck strebt, damit er aus der Gewaltherrschaft zur Gemeinschaft der

1 Ibid., S. 93

2 Ibid., S. 96 
Liebe fähig wurde. Sie ist Dietrichs in sichtbare Erscheinung getretene Seele.

Durch Irene spricht der Dichter hier vielleicht mehr noch als durch Dietrich. Sie steht hier als Sendbotin des Dichterhimmels, da. Irene gleicht selbst der Feuerlilie, die Dietrich sich zum Wahrzeichen im "Platz" gewählt hat, und die der Glanz des heissersehnten Paradieses werden soll. In dieser Dichtung kommt Dietrichs Irrweg zu Ende. Sei(ne letzte Erkenntnis soll sie nie mehr voneinander trennen: Hitzen und Frósten widerstehen müssen. so auch die Liebe. Dann erst wird es - Liebe. 1

Thre Liebe hat alle Niederungen des Triebes bestanden. Zwar finden beide den Tod, als die Brücke explodiert. Aber der Geist des Friedens und der Liebe hat eine Heimstatt in der Welt gefunden. Anscheirend sind Dietrich und Irene gescheitert. Aber auf diesem Scheitern liegt aller menschliche Glanz; sie vertreten das Hohere, das Recht in einer schlechten Welt. Äusserlich scheitern sie, aber innerlich erringen sie den Sieg. Denn das ist ihre Bedeutung, dass sie durch ihren Anfang und Beispiel andern den Weg gebahnt haben. Ihre Zeit ist zu Ende, aber ihre Wirkung nicht.

Viele folgen ihrem Beispiel. Da ist der Major, der an der Spitze der Gewaltigen den Störer Dietrich schnell zu überwältigen glaubt, der

1 Ibid., S. 99. 
am Ende aber ihre Haltung so bewundert, dass er sagt: "Ich liebe Dich ! Euch beide !" 1 Die grösste Erkenntnis enthüllt sich aber im feigen Sohn, wenn er die Feuerlilie in die Hand nimmt und die ewige Botschaft Dietrichs weiterträgt.

So leben Dietrich und Irene ihr Streben nach Erlösung unter dem befreienden Drang des "ich liebe" der Vollendung entgegen. Noch ein* mal hat hier Fritz von Unruh das Liebesethos aus "Platz" in vertiefter Bewusstheit zum Ausdruck gebracht. Stärker als der von Zweifeln zer(9issene Mann, schleudert Irere das sammelnde, die Lebensidee des Hichters ganz klar aussprechende Wort "Vernunft der Liebe" in die Welt. Während sich im "Platz" die Liebeseinheit gerade erst entwik"kelt hat, lebt in "Dietrich" das Ethos der Liebe schon in Dietrich und Irene. Thre Liebeseinheit dient als Beispiel in der neuen Welt. In Dietrich enthullt sich der Friedenskampf des Dichters. Als Missionar fährt Dietrich zu den anderen, der Gegnern von einst in "Platz", um zu erkunden, wie es bei ihnen steht, ob auch sie der gleiche Wille beseelt, die Welt durch Friede und Liebe neu zu gestalten. Er findet Freunde in der Dorfgemeinschaft. Er trifft aber auch die böswilligen Verneiner, die alten Hasser. Er sieht die Welt noch immer wie vorher und macht kein Hehl aus seiner Enttäuschung und seinem Zorn. Er predigt leidenschaftlich seinen Gott der Liebe und des FrieIbid., S. 82. 
dens.

Aber seine Predigt bleibt für einige, wie Schleich, nur ein Anruf. Dieser ist und bleibt der Verneiner. Vielleicht hat Unruh ihn mit $\mathrm{Ab}-$ sicht so dargestellt. Denn der dritte Teil der Trilogie enthält die Selbstkritik des expressionistischen Stils. Und zwax spüren wir dies it der Schleich-Gestalt. Im "Platz" benützte Schleich das TelegrammGokabular zur Befriedigung seiner unterdrückten Macht. In "Dietrich" ist Schleich inzwischen so reich geworden, dass er Wicht mehr zu heucheln braucht und bekennt, "gerne lass ich die andern औügen und betr. ügen! ${ }^{1}$ Seine bekannten Satzverkürzungen sind fast verschwunden. Der splitternde Dialog weicht hier dem breiten Strom der Rede, und klangvollere Wortbildungen greifen Platz. Wir bemerken in diesem T'eil Züge ins Romantische. Das Streben nach einem Ideal ist offenbarer als in den zwei ersten Teilen. Die Darstellung von zum Teil symbolisch zu begreifenden Personen, wie Schleich und Miss Universe, die Bevorzugung des Dämmerigen und des Mondlichts, das Traum-und Gespensterhafte, wie die Begegnung Dietrichs mit seinem Bessern Ich, sind Merkmale der neuromantischen Symbolistik. Ein Wille ist überall durchzuspüren, ein Wille, der die Welt neu gestalten will. Zwar bleibt die Erfülllung der Sehnsucht versagt. In Wirklichkeit kann seine neue We lt nicht gestaltet werden. Sie bleibt nur eine Idee.

1 Ibid., S. 75 . 


\section{KAPITEL V}

\section{DIE IDEE DER NEUEN WELT}

Die Idè der neuen Welt, wie Unruh sie erträumt und ersehrt,liegt unerreichbar weit in fernen Räumen. Aber deshalb verzichtet er nicht darauf, sich ihr zu nähern. Unruh ist Optimist; er glaubt an eine bessere Zukunft, er dichtet sich in glühenden Visionen an sie heran. Visionen spielen in seinen Werken eine grosse Rolle. Teilweise dienen. sie dazu, uns die zukünftige Entwicklung voraussehen zu lassen; teil-... weise aber auch soll der Held die Hoffnung seines Lebens wenigstens im Traum verwirklicht sehen.

Sein Zukunftstraum hat einen festen Kern, und der heisst "Pflicht". Dieser Begriff ist tief in ihm verwurzelt, hat sich aber gewandelt und veredelt. Als Kadett erscheint ihm die Pflicht als angeerbte Mission, denn fast alle Unruhs standen im Dienst der herrschenden Gewalt. Als Offizier.wagt der Dichter es, den Pflichtbegriff in seinen Erstlingsdra men auseinanderzusetzen. Hier ist es noch die Pflicht des Gehorsams gegen den Befehl des Vorgesetzten, die zu innern Kämpfen oder zur Unterwerfung führt. Dann weitet sich Unruh der Blick ins allgemein Menschliche. Er sieht eine Pflicht, die hoch "uber dem "du sollst" steht. Sie'gipfelt in dem Satze: "Ich will und liebe". Im Strudel des Krieges 
schreibt er das Gedicht "Vor der Entscheidung", in dem er die neue Pflicht formuliert. Nur weil die Umwandlung der Pflicht von vornherein, trotz aller Blutvererbung tief in Unruhs Natur begründet liegt, konnte der Krieg so a uf ihn wirken, wie er gewirkt hat. Anders ist nicht zu begreifen, dass er, während die meisten im Siegestaumel schwelgten, die moralische Verwüstung mit bitterster Qual des eigenen Herzens spür, und dass er hinter dem Kriegschaos den Himmei einer I besseren Welt ersehnte. Im Krieg "uberfällt ihn die Ahnung von dem Weid der Menschen, und er schwört, für das "Sein", das Lueben, und gegen das "Nichtsein", den Staat, zu kämpfen. Denn im Schlachtfeld vernimmt Unruh den Schrei nach Leben aus dem röchelnden Mund der. sterbenden Kameraden. Er sieht ihre brechenden Augen nach Leben verlangen und stellt sich entschlossen in den Dienst der Menschheit.

Der Grundsatz der Pflicht ist auch das Leitmotiv f'tur seine Trilogie. Wie dieses Prinzip sich in ihr wandelte, wie es aus der Kaserne in den Horizont der ganzen Menschheit hinauswächst, ist ergreifend. Es ist auch der Kern, von dem jede Betrachtung seiner neuen Weltgestaltung ihren Ausgang nimmt. Sein Kriegsgedicht und die Trilogie zusammen enthüllen die Idee der neuen Welt. In dem ersten Teil stellt ex die Mutter als die alte Welt und als Gebärerin der neuen Welt dar. Der Ursprung einer neuen gewaltigen Wandlung wird dieses Weib: einer Wandlung der Welt aus dem Geiste der Mütterlichkeit. Nicht mehr eine Wandlung aus der Empörung in der Not, wie alle Revolutionen 
vorher es waren, bricht hier an, sondern eine Wandlung aus den ursprünglichen Kräften der Welt an sich, aus den Kräften der Mutter. "Aus Deiner Seele ward der Tag geboren! Er lebt !" 1, ruft der jüngste Sohn der Mutter zu, so den Anbruch der Wandlung verkündigend. Aus ihrem Herzblut wird sich die Welt erneuern. Was Unruh uns bisher gab, war das Erwachen einer neuen Kraft. Der Erbe dieser Kraft ist Dietrich.

Vom "Chaos zu einer Ordnung fuhrt uns Unruh im "Platz", indem er die Pflicht neu gestaltet. Durch Irene versetzt Dietrich sich in die Lage, die Welt zu gestalten. Sie fordert, ehe die Welt neu und besser exsteht, dass das Leben von Liebe entsünnt werde: "Liebe nur schafft neue Liebe, darum lebe um zu lieben !" 2 Dann erst, wenn alle so glauben und fühlen, wird die Menschheit erster Tag heraufdämmern. Hier verkundet Unruh, was seinem ursprünglichen Willen gemäss ist: den ewigen Sinn der Lebenseinheit von Mann und Weib und der-sich daraus entwirkenden Kräfte reiner Menschlichkeit, Gerechtigkeit und Freiheitsfähigkeit.

In "Dietrich" zeigt der Dichter uns die aus der Liebeseinheit aus wirkende Entwicklung. Die Verkündigung der neuen Welt exeignet sịch in diesem Drama nicht in positiver Art, sondern in negativer Art. Der

1 Unruh, Ein Geschlecht; S. 64.

2 Unruh, Platz, S. 78. 
Sinn der Verkündigung liegt nicht in dem, was sich erfüllt, er liegt im unerfullten Geschehen. Nur in der. Begegnungsszene zwischen Dietrich thd den Machthabern steht die positive Verkundigung an der Grenze der Durchbrechung. Aber gerade dieser Drang J"ässt die Gestaltung der Welt in so durchgeistigter Art erscheinen, dass der ewige Gehalt die Form in einen fast transparenten Zustand erhebt und so in das gegenwärtige L̇eben zu leuchten vermag. Die Erfüllung in der Wirklichkeit blieb der Sehnsucht versagt. In diesem Sinne ist Unruh ein Dichter der Sehnsucht. Er vertritt die Idee, die den Menschen Heilung von schwefen Übeln verspricht. Er lebt und schwebt in dieser Idee, die er verwirklichen will. Er fordert von den Menschen, dass sie ihr Leben ändern um der Weltgestaltung willen. Wer aber wäre bereit, sein Leben und sich selbst zu ändern? Es ist doch zu unsicher, zu wenig garantiert, was dabei herauskäme.

Der Dichter macht seinem Namen Ehre - er beunruhigt die Gemü ter die in Ruhe gelassen sein möchten. Dabei hat Unruh keine dauernde chaotische Unruhe im Sinne, im Gegenteil, was er wünscht, ist ja gerade eine bessere Ordnung des Daseins und der Menschheitsverhältnis se, die nicht mehr von den Dunkelmächten der Gewalt bedroht ist. Nicht anders ist die Zukunftvision des Dichters. Das aber klingt ungemein politisch. In der Tat: Fritz von Unruh ist ein politischer Dichter. Es gibt keine Dichtung Unruhs, die nicht von Politik bestimmt wäre. Und wenn Politik in der tiefsten Bedeutung des Wortes das Verhältnis 
des Einzelnen zu einex Gesarntheit in sich begreift, so ist er der ewig politische Dichter. Ein Polis oder Politeia ist immer vorhanden. Sie heisst in "Offiziere" preussisches Militar, in "Louis Ferdinand" Preus sen, in "Vor der Entscheidung" Soldat, in "Geschlecht" Menschheit, in "Platz" Revolution und in "Dietrich" die neue Welt. Aber heisst das ein undichterisches Unternehmen? Unruh selbst hat diesen Vorwurf einmal abgewehrt, indem er in seiner Schillerrede darauf hinwies, dass seit den attischen Tragikern bis zu Schiller jede echte Dichtung "auf höherer Elene immer politisch" gewesen sei. 1 Einer aber, der in solchem Sinne das Dichteramt versteht, wird nur in seltenen F"llen ein scharfsinniger Intellekt sein, er wird, um sich verständlich zu rnachen, sich auf anderes stützen. So auch Fritz von Unruh. Was er geschaffen hat, war nie Gehirnprodukt, es war Produkt des Gefühles. Er schrieb und schreibt immer aus ganzem Herzen und ganzer Seele.

Das Motto Unruhs Kunst ist nicht 1'art pour 1'art, sondern l'art pour l'action. Er will nicht bloss die Kunst fúr die Kunst, sondern er will, dass die Menschen durch die Kunst anders werden, dass sie sich wandeln. Die Kunst hat Ziele und exstrebt Wirkungen, die ausserhalb des rein künstlerischen Gebiets liegen. 1

Seine Kunst ist die der Expressionisten. Auch er fuhlt, dass eine neue Zeit, ein neuer Mensch kommt. Von solcher Sehnsucht ist seine

1 Diebold, S. 429. 
Kunst getragen. In der Trilogie verwirklicht der Dichter seine Sehnsucht in den Helden. Thre Worte springen in die Herzen der Zuhörer und zünden dort als zeugende Flamme. Sie beschworen die Kräfte in den Menschen: die Kräfte der Gerechtigkeit, des Friedens und der Liebe. Alles wird aber zu einer Forderung an den Menschen: sich selbst zu gestalten, in sich selbst erst zu bauen und Krafte zu wecken, denn alle Weltertscheidung liegt im Herzen des Menschen. Unruhs Sehnsucht; seire Idee ist die der Kraft und des kärnpferischen Mutes. Er vertritt eimen Kampf, der unendlich schwerer ist als der Kampf mit der Waffe: den Kampf des Herzens und der Vernunft und der Verantwortlichkeit dem Leben gegenüber. Denn nicht nur aus der Kraft des Herzens soll der Mensch leben, sondern auch aus der Kraft der Vernunft; doch eines diene dem andern. Das Herz muss an die Stirne klopfen; es gilt den Bund des Geistes mit dem klopfenden Herzen.

Die Zahl der Jahre, das Ausmass der Eriebnisspannungen verhinderten die Entwicklung seiner Idee nicht. Er erreicht den Ausgleich von Idee und Wirklichkeit, von Zeit und Ewigkeit in der Trilogie. Sie steht im Dienst der Ewigkeit. Sie ist wie das Leben, ein Ringen aus der Zeit in die Ewigkeit. Aus den drei Zeitformen ist es vor allem die Zukunft, in die die Trilogie zu mündenscheint. Gegen die Vergangenheit läuft der Dichter Sturm, obwohl er ihr als Mensch in seinem adeligen Ursprung verpflichtet ist. Das Erlebnis der Gegenwart ist für Unruh der Krieg. So wurde "Vor der Entscheidung", die würdige Ge- 
staltung dieses Erlebnisses. Aber gerade durch das Kriegserlebnis war im Dichter die Idee einer neuen Welt ausgel'óst. Die Zukunft aber wird sie sich doch noch zu einer Friedens - und Liebeswelt formen, die der Idee des Dichters annähernd gleicht? Dann wird man vielleicht einmal sagen: in der Trilogie Unruhs habe sich die Mythologie einer neuen Welt angekundigt; eine Welt, in der die Menschen in Frieden leben können. 


\section{BIBLIOGRAPHIE}

\section{Bucher}

Bab, Julius. Der Wille zum Drama: Deutsches Dramenjahr, 1911 1918. Berlin: Oesterfeld und Co., 1919

Biese, Alfred. Poesie des Krieges. Bd. I. Berlin: Erich Reiss Verlag, 1.915

Diebold, Bernhard. Anarchie im Drama: Kritik und Darstellung der roodernen Dramatik. 4. Auflage. Berlin: Heinrich Keller Verlag, 1965.

Duwe, Wilhelm. Ausdrucksformen deutscher Dichtung: Vom Naturalismus bis zur Gegenwart. Berlin: Erich Schmidt Verlag, 1965.

- Deutsche Dichtung des 20. Jahrhunderts: Vom Naturalismus zum Surrealismus. Bd. Il. Zurich: Orell Fussli Verlag, 1962 .

Edschmid, Kasimir. Briefe der Expressionisten. West-Berlin: Ul].stein Verlag, 1964.

- Frühe Manifeste: Epochen des Expressionismus. Darmstadt: Hermann Luchterhand Verlag, 1960.

- Lebendiger Expressionismus: Auseinandersetzungen, Gestalten, Erinnerungen, Munchen: Desch Verlag, 1961.

- Ueber den Expressionismus in dex Literatur und die neue Dichtung. Berlin: Erich Reiss Verlag, 1921.

Emmel, Felix. Das Ekstatische Theater. Prien am Chiemsee: Kampmann und Schnabel Verlag, 1924.

Eechter, Paul: Das Europäische Drama. Bd. II und III. Mannheim: Bibliographisches Institut A.G. , 1.957-1958. 
Freyhan, M. Das Drama der Gegenwart. Berlin: Erich Reiss Verlag, 1922

Garten, H. F. Modern German Drama. London: Methuen and Co., Ltd. , 1959

Goethe, Johann, Wolfgang. Epen, West-Oestlicher Divan, Theatergedichte. Zürich: Artemis Verlag, 1959.

Knevels, Wilhelm. Das moderne Drama. 2. Auflage. Braunschweig: Wollermann Verlag, 1930 .

- Expressionismus und Religion: Gezeigt an der neuesten deutschen expressionistischen Lyrik. Zurich: Mohr Verlag, 1927.

Kuchler, Walter. Romain Roland, Henry Barbusse, Fritz von Unruh: Vier Vortrage. Nurnberg: Hans Car:1 Verlag, 1957.

Mann, Otto. Geschichte des deutschen Dramas. Stuttgart: Alfred Króner Verlag, 1963.

Naumann, Hans. Dichtung der Gegenwart: Vorn Naturalismus bis zum Expressionismus. Stuttgart: Metzler Verlag, 1930.

Pinthus, Kurt. Menschheitsdämmerung: Ein Dokument des Expressio-. nismus. Hamburg: Rowohlt Verlag, 1959.

Raabe, Paul. Expressionismus: Aufzeichnungen und Erinnerungen der Zeitgenossen. Freiburg: Walter Verlag, 1965.

- Greve, Ludwig. Expressionismus: Literatur und Kunst 1910-1923. (Eine Ausstellung des deutschen Literaturarchivs im Schiller -Nationalmuseum Katalog). Marbach: Deutsche Schillergesellschaft, 1960.

Rasche, Friedrich (Hrsg.). Fritz von Unruh: Rebell und Verkünder. Hannover: Verlag fur Literatur und Zeitgeschehen, 1960.

Sokel, Walter. Der literarische Expressionismus. München: Albert Langen und Georg Muller Verlag, 1959.

Staiger, Emil. Grundbegriffe der Poetik. 4. Auflage. Zürich: Atlantis Verlag, 1959. 
Szondi, Peter. Theories des moderner Dramas. Frankfurt/Main: Suhrkarmp Verlag, 1959.

Toller, Ernst. Eine Jugend in Deutschland. Berlin: Erich Reiss Verlag, 192.2.

Wanderscheck, Hermann. Deutsche Dramatik der Gegenwart. Berlin: Bong Verlag, 1938.

Unruh, Frjedrich Franz von. Gesinnung. Werther a. Teutoburger Wald: Fackelreiter Verlag, 1924.

Unruh, Fritz von. Der Sohn des Generals. Nürnberg: Hans Car]. Verlag, 1957 .

Dramen. Nürnberg: Hans Carl Verlag, 1960.

- Ein Geschlecht. München: Kurt Wolff Verlag, 1917.

- Mächtig seid ihr nicht in Waffen: Reden. N"ürnberg: Hans Cari Verlag, 1957.

- Opfergang. Berlin: Erich Reiss Verlag, 1919.

- Vor der Entscheidung. Berlin: Erich Reiss Verlag, 1919.

- Platz. Müchen: Kurt Wolff Verlag, 1920.

- Vaterland und Freiheit: Eine Ansprache an die deutsche Jugend. Berlin: Franz Schneider Verlag, 1923.

\section{Zeitschriften}

Diebold, Bernhard. "Ein Geschlecht" Das Literarische Echo, XX, 21. Heft (Berlin: Egon Fleischel Verlag und Co., 1917-1918), $1296 f$.

Enge1, Fritz. "Fritz von Unruh und seine besten Bühnenwerke", Schneiders Bühnenfuhrer, (Berlin, 1922), S. 7-2.5.

Geyer, Wilhelm. "Fritz von Unruh, Versuch einer Deutung, "Deutsche Zukunft, hrsg. von Carl Dietz, 4. Heft (Rudolstadt, 1924), S. $15 \mathrm{ff}$. und $27 f$. 
Goldtschmidt, Rudolf. "Fritz vor Unruh", Dichter und Bühne, (Augsburg, 1921), S. 3ff.

Huebner, Friedrich, Markus. "Krieg und Expressionismus, "Die Schaubühne, hrsg. von S. Jacobson, X (Berlin, 1914), S. $441-443$.

Korodi, Eduard, "Fritz von Unruh", Der Lesezirkel, V, 7. Heft. (Zürich, 1917-1918), S. 102f.

Meister, Robert, "Fritz von Unruh", Germanische Studien, 39. Heft Perlin, 1922), s. $171 \mathrm{f}$.

Mühlestein, Hans. "Europäische Kulturgegensătze", Handbuch der Politik, V (Berlin, 1922), S. $171 \mathrm{f}$.

Petersen, fulius. "Fritz vonUnruh", Das Literarische Echo, XX, 9. Heft (Berlin: Egon Fleischel. Verlag und Co., 191.7-1.918), S. 50].ff.

Picard, Max. "Expressionismus", Die Erhebung, Bd. I (Berlin, 1919), S. $332,-338$.

Sternaux, Ludwig. "Ein Geschlecht", Vossische Zeitung, (30. Dezember, 1918), S. 5.

Walzel, Oskar. "Fritz von Unruh", Germanisch-Romanische Monatsschrift, (Heidelberg, 1921), S. $220 \mathrm{ff}$. und $267 \mathrm{ff}$.

Andere Quellen

Brief des Hauptmanns G. Schelle an Kurt von Unruh (Stuttgart, 9. April, 1924).

Brief Kurt von Unruhs aus Roding, März, 1967.

Persönliche Unterhaltung mit Kurt von Unruh, München, März, 1967.

Unruh, Fritz von. Dietrich. Unveröffentliches Drama, Diez an der Lahn, 1958. (Manuskript). 